A N N A L E S Annales de Bretagne et des Pays de l'Ouest

Anjou. Maine. Poitou-Charente. Touraine

108-3 | 2001

Varia

\title{
Collégiales urbaines et collégiales castrales dans le diocèse d'Angers au Moyen Âge
}

Jean-Michel Matz

\section{OpenEdition}

\section{Journals}

Édition électronique

URL : http://journals.openedition.org/abpo/1693

DOI : $10.4000 /$ abpo. 1693

ISBN : 978-2-7535-1483-6

ISSN : 2108-6443

Éditeur

Presses universitaires de Rennes

Édition imprimée

Date de publication : 20 septembre 2001

Pagination : 5-33

ISBN : 978-2-86847-625-8

ISSN : 0399-0826

\section{Référence électronique}

Jean-Michel Matz, «Collégiales urbaines et collégiales castrales dans le diocèse d'Angers au Moyen Âge », Annales de Bretagne et des Pays de l'Ouest [En ligne], 108-3| 2001, mis en ligne le 20 septembre 2003, consulté le 02 mai 2019. URL : http://journals.openedition.org/abpo/1693 ; DOI : 10.4000/ abpo.1693 


\title{
Collégiales urbaines et collégiales castrales dans le diocèse d'Angers au Moyen Âge
}

\author{
Jean-Michel MATZ \\ Maître de conférences en histoire médiévale \\ HIRES, UPRES EA 1710, Université d'Angers
}

Il fut un temps où les historiens négligeaient le monde des chanoines séculiers, considérant avec dédain que ces clercs de deuxième rang ne pouvaient soutenir la comparaison avec les communautés de moines ou de religieux vivant dans la perfection. Le jour n'est pas encore venu où l'on publiera trop sur les chanoines, mais ces considérations anciennes ne sont plus de mise aujourd'hui; la situation historiographique est fort heureusement en plein renouvellement, notamment avec une équipe de recherche dirigée par Hélène Millet qui a entrepris l'étude systématique des chanoines des cathédrales françaises ${ }^{1}$. Les chapitres cathédraux retiennent normalement l'attention en premier lieu, mais il ne faudrait pas négliger pour autant les églises collégiales qui restent moins bien connues, en dehors d'études de cas et de quelques enquêtes plus larges ${ }^{2}$. Les collégiales doivent leur nom au fait d'être desservies par un collège séculier

1. Ce groupe du CNRS est baptisé Fasti Ecclesiae Gallicanae. Répertoire prosopographique des évêques, dignitaires et chanoines des diocèses de France de 1200 à 1500 : quatre volumes ont déjà été publiés depuis 1996, éd. Brepols (Amiens, Rouen, Reims, Besançon), et à paraître en 2001, CoMTE, François et MATZ, Jean-Michel, Tome 5 : le diocèse d'Angers. En parallèle au travail de l'équipe des Fasti s'est constitué un groupe de travail sur les collégiales.

2. Parmi les travaux monographiques, on relèvera ceux de Jean BECQUET sur le Limousin, dans le Bulletin de la Société Archéologique du Limousin, t. 102, 1975, p. 69139, et ceux du chanoine Michel VeISSIERE sur deux collégiales de Provins (publiés en 1961 et 1998); d'autres études sont citées infra. Pour les enquêtes plus larges : "Le monde des chanoines (XI ${ }^{\mathrm{e}}$-XIV ${ }^{\mathrm{e}}$ siècles) ", Cahiers de Fanjeaux, xxIv, Toulouse, 1989 (sur le Midi); "Recherches sur l'économie ecclésiale à la fin du Moyen Âge : autour des collégiales de Savoie ", Mémoires et documents publiés par l'Académie salésienne, t. 97, 1991 ; TABBAGH, Vincent, "Un projet de recherches : les collégiales de Bourgogne au Moyen Âge ", Annales de Bourgogne, t. 71, 1999, p. 99-118. Voir aussi le bulletin critique de Jacques PycKe, "Cathédrales, collégiales et chanoines séculiers ", Revue d'Histoire Ecclésiastique, t. 86, 1991, p. 355-371. 
de chanoines formant chapitre, vivant des revenus de leurs prébendes et des distributions quotidiennes rétribuant leur présence à la célébration de la messe et de l'office divin. L'heure de la synthèse n'a donc pas encore sonné pour elles ${ }^{3}$, et seule l'accumulation d'études monographiques dans une perspective d'histoire comparative la rendra un jour possible. Je me propose donc de présenter les résultats d'une recherche sur les collégiales des campagnes du diocèse d'Angers, de leur fondation jusqu'à la fin du Moyen $\widehat{A} \mathrm{e}^{4}$, en la plaçant dans une problématique d'histoire sociale au sens large plus que dans une perspective strictement religieuse.

La période de fondation des collégiales s'ouvre en général à l'époque carolingienne, à l'initiative d'évêques, de princes et de seigneurs soucieux du salut de leur âme, mais aussi de l'affirmation de leur prestige et de la défense de leurs intérêts temporels ${ }^{5}$. Ainsi, à Angers, les premiers chapitres séculiers apparaissent au IX ${ }^{\mathrm{e}}$ siècle, dans des basiliques cimetériales fondées par d'anciens évêques, mais au siècle suivant, des moines noirs remplacent des chanoines à Saint-Aubin et Saint-Serge d'Angers. Le caractère incertain de ces premières expériences s'explique par la confusion qui a longtemps régné entre profession monastique et canoniale, par l'absence, dans l'Ouest, d'une réforme des chanoines au cours des $\mathrm{X}^{\mathrm{e}}$ et $\mathrm{XI}^{\mathrm{e}}$ siècles, et par le flou de la terminologie. Dans le reste du diocèse, la forte densité du réseau monastique avec des établissements anciens à la tête de nombreux prieurés - semble avoir retardé l'essor du monde canonial : aucun chapitre séculier n'est antérieur à l'an 1000, mais entre le Xle et le début du XVI ${ }^{\mathrm{e}}$ siècle, 16 collégiales ont été fondées dans les bourgs ou les petites villes du diocèse d'Angers, parmi lesquelles 6 n'ont eu qu'une existence temporaire (voir carte).

Cet échantillon, comparé aux régions voisines, permet déjà de relever des disparités dans l'implantation des chapitres séculiers : le diocèse d'Angers est mieux pourvu que ses voisins de Bretagne ou du Mans, où les collégiales se trouvent principalement en milieu urbain; avec 17 chapitres (dont 7 à Angers), il présente une situation proche du diocèse de Poitiers (20 chapitres), alors pourtant plus étendu ${ }^{6}$, et aujourd'hui bien

3. Seul un juriste, dans une perspective d'histoire du droit et des institutions, l'a tentée : LEgIER, Henri-Jacques, Les églises collégiales en France, des origines au XVe siècle, Thèse dactylogr. de la Faculté de Droit de Paris, 1955.

4. J'ai présenté ailleurs les premiers résultats d'une enquête sur les collégiales de la ville d'Angers : MATZ, Jean-Michel, " Chapitres et chanoines séculiers d'Angers à la fin du Moyen Âge (milieu XIV e-début XVI e siècle) ", Archives d'Anjou. Mélanges d'Histoire et d'Archéologie angevines, t. 3, 1999, p. 33-53; les établissements de chanoines réguliers ont été étudiés par François COMTE, "L'implantation des chanoines réguliers dans le diocèse d'Angers aux XII ${ }^{\mathrm{e}}$-XIII ${ }^{\mathrm{e}}$ siècles : le rôle des évêques ", Naissance et fonctionnement des réseaux monastiques et canoniaux, (actes du colloque du CERCOR, Saint-Étienne, 1985), Saint-Étienne, 1991, p. 409-423.

5. DEREINE, Charles, article "Chanoines ", Dictionnaire d'histoire et de géographie ecclésiastiques, t. 12, Paris, 1953, col. 353-405.

6. FAVREAU, Robert, « La résidence dans les chapitres du diocèse de Poitiers au Moyen Âge ", Crises et réformes dans l'Église, de la Réforme grégorienne à la Préréforme (Actes du colloque d'Avignon, 1990), Paris, 1991, p. 39-54 : 5 chapitres à Poitiers même, 15 dans le diocèse, surtout à l'est. 
documenté. La documentation pour l'Anjou est malheureusement moins riche et déséquilibrée, à la fois dans le temps, entre établissements, et qualitativement; si les sources font parfois défaut pour l'époque des premières fondations, elles présentent encore des lacunes pour étudier ces établissements aux derniers siècles du Moyen Âge. L'intérêt de l'enquête n'en est pas moins évident, tant pour l'histoire religieuse que pour l'histoire de l'économie ou de la société, avec par exemple la question du rôle des collégiales dans le développement urbain des bourgs et des petites villes. Nous essaierons donc dans un premier temps de rappeler le mouvement des fondations qui s'est réalisé ici en deux phases distinctes. Il conviendra ensuite d'étudier l'organisation, le fonctionnement interne et le recrutement des chapitres, pour analyser enfin leurs fonctions dans la société des campagnes du diocèse d'Angers à la fin du Moyen Âge.

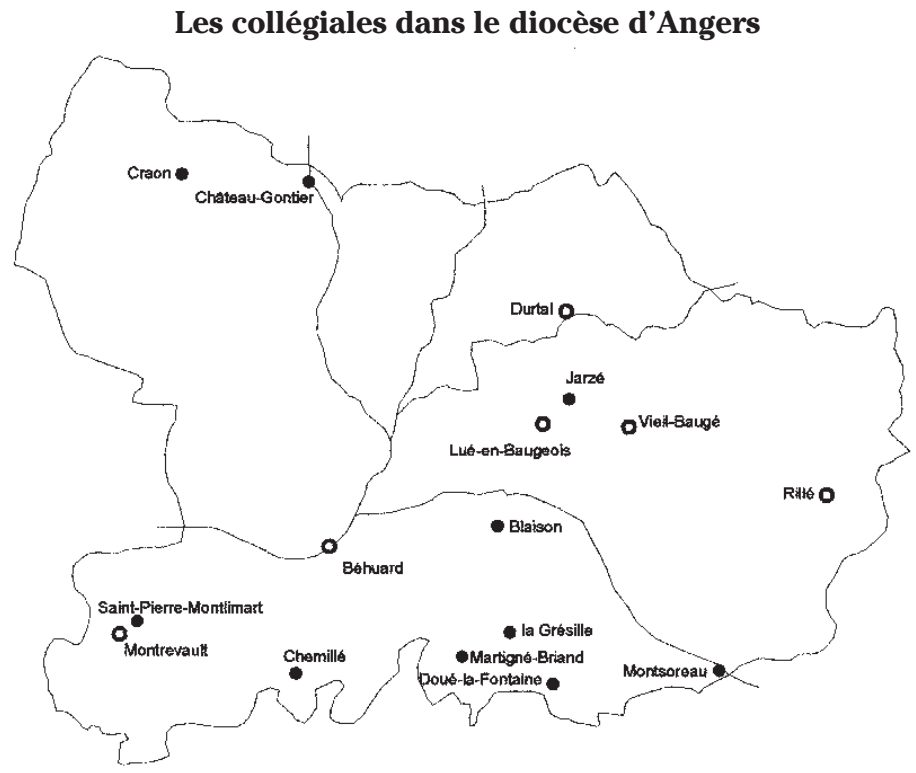

(classement alphabétique des lieux)

- : Collégiales éphémères

Béhuard, Notre-Dame (1481)

Durtal, Notre-Dame (avant 1059)

Lué-en-Baugeois, Notre-Dame (avant 1136)

Montrevault, Saint-Nicolas (1106)

Rillé, Notre-Dame et Saint-Loup (vers 1040)

Vieil-Baugé, Saint-Symphorien (avant 1050)

\section{- : Collégiales pérennes}

Blaison, Saint-Aubin (1020), 4 prébendes

Château-Gontier, Saint-Just (avant 1080), 4 prébendes

Chemillé, Saint-Léonard et Saint-Barthélemy (vers 1090), 8 prébendes
Craon, Saint-Nicolas (entre 1078 et 1095), 6 puis 8 prébendes

Doué-la-Fontaine, Saint-Denis (vers 1063), 4 puis 8 puis 6 prébendes

La Grésille, Notre-Dame-des-Vertus (1455), 5 prébendes

Jarzé, Saint-Cyr et Sainte-Julitte (1500), 5 prébendes

Martigné-Briand, Saint-Simplicien (avant 1123/1125), 6 prébendes

Montsoreau, Sainte-Croix (1520), 6 prébendes

Saint-Pierre-Montlimart (vers 1250), 8 prébendes 


\section{Les fondations}

\section{Une première vague (XI ${ }^{e}$-milieu $X I I^{e}$ siècle)}

En un siècle environ, 11 chapitres ont en effet été établis dans des églises, témoignant à la fois d'une réelle fermentation spirituelle et des mutations de la société ${ }^{7}$. Qu'il ait des racines anciennes ou qu'il naisse au tournant $\mathrm{du} \mathrm{XI}^{\mathrm{e}}$ siècle, le mouvement de fondation est étroitement lié à l'histoire de la société. Avec le morcellement des pouvoirs jusqu'aux mains des châtelains, l'" âge seigneurial " correspond à la principale période de fondation des collégiales en Anjou ${ }^{8}$. Comme l'ont montré JeanMarc Bienvenu et Joseph Avril, l'état de la documentation conservée ne permet pas toujours de retrouver les circonstances précises des fondations, mais il faut d'emblée souligner qu'à une exception près, Montrevault, tous ces chapitres découlent d'une initiative seigneuriale et non de l'action directe de membres du clergé. Les collégiales fondées semblent relever de deux modèles différents : les unes naissent dans le but de mieux organiser la desserte de centres d'habitat en plein développement, alors que les autres ont d'abord une vocation funéraire, qu'elles soient établies dans des chapelles de châteaux ou dans des églises paroissiales.

Plusieurs collégiales n'ont eu qu'une existence temporaire, leur échec s'expliquant en général par la rivalité avec un établissement monastique crispé sur ses prérogatives et sa volonté de conserver un monopole dans l'implantation ecclésiastique locale. Au Vieil-Baugé, un chapitre de chanoines est ainsi attesté au milieu du XI ${ }^{\mathrm{e}}$ siècle ${ }^{9}$, mais à la fin du siècle le seigneur du lieu donna l'église Saint-Symphorien à l'abbaye Saint-Serge d'Angers, donation confirmée par son fils Hugues de Beaupréau en $1148^{10}$. À Durtal, les moines de Saint-Aubin d'Angers, installés dans le prieuré de Gouis, s'opposèrent à ce que la chapelle castrale Notre-Dame, desservie par des chanoines séculiers, soit érigée en paroisse; ils finirent par en obtenir la restitution par Agnès de Clervaux, veuve du seigneur Hubert

7. On se reportera pour cette période à BIENVENU, Jean-Marc, Recherches sur le diocèse d'Angers au temps de la Réforme grégorienne ( $X l^{e}$-première moitié $\left.X I{ }^{e}\right)$, thèse $3^{\mathrm{e}}$ cycle dactylogr., Univ. Paris-Sorbonne, 1968, notamment p. 129-137; AvRIL, Joseph, Le gouvernement des évêques et la vie religieuse dans le diocèse d'Angers (1148-1240), LilleParis, 1984, 2 vol.; Locatelli, René, Sur les chemins de la perfection. Moines et chanoines dans le diocèse de Besançon (vers 1060-1220), Saint-Étienne, 1992, étudie un contexte similaire.

8. ZADORIA-RIO, Élisabeth, "Construction de châteaux et fondation de paroisses en Anjou aux XI ${ }^{\mathrm{e}}$ et XII ${ }^{\mathrm{e}}$ siècles ", Archéologie médiévale, 1979, p. 115-123; GuILlot, Olivier, Le comte d'Anjou et son entourage au XI ${ }^{e}$ siècle, Paris, 1972, 2 vol. Sur le contexte politique général, LEMARIGNIER, Jean-François, "Aspects politiques de la fondation des collégiales dans le royaume de France au XI ${ }^{\mathrm{e}}$ siècle ", La vita commune del clero nei secoli $X I^{e}-X I I^{e}$ (Atti della Settimana di studio, La Mendola, 1959), Milan, 1962, t. 1, p. 19-40 (ici p. 25).

9. Marchegay, Paul, "Recherches sur le Vieil-Baugé ", Revue de l'Anjou, 1852, p. 277288 , et 1853 , p. $71-81$.

10. Arch. dép. du Maine-et-Loire, $\mathrm{H} 1240, \mathrm{n}^{\circ} 1$. 
de Champagne, vers 1059 , ce qui fut fatal pour le chapitre ${ }^{11}$. Aux confins de la Touraine, à Rillé, une collégiale desservie par 4 chanoines fut fondée vers 1040 par Airaud, premier seigneur connu de ce domaine; son gendre Geoffroi, ayant semble-t-il eu à se plaindre de la négligence des chanoines, résolut en 1063, avec l'accord de l'évêque d'Angers, de les remplacer par des moines venus de l'abbaye tourangelle de Marmoutier qui menait alors une politique très entreprenante de multiplication de ses prieurés en Anjou ${ }^{12}$.

Ces exemples montrent l'importance des restitutions en faveur des monastères au cours du $\mathrm{XI}^{\mathrm{e}}$ siècle, mais l'épanouissement de la réforme dite grégorienne allait toutefois promouvoir par la suite la restitution des églises entre les mains des évêques du diocèse. C'est ainsi que l'église castrale Notre-Dame de Lué, desservie par un " chapitre » de deux prébendes, fut rendue par son fondateur à l'évêque d'Angers Ulger (1125-1148), entre 1136 et 1138, en échange de la promesse du prélat de faire célébrer dans la cathédrale un anniversaire pour le donateur et sa famille, mais les chanoines disparurent ensuite ${ }^{13}$. Le dernier cas de collégiale avortée détonne par la personnalité de son fondateur. À Montrevault, première forteresse des Mauges, le vicomte Raoul II fit bâtir une chapelle dédiée à saint Nicolas et la donna aussitôt à la cathédrale d'Angers en 1095; en 1106, les chanoines de la cathédrale y établirent un collège de 6 prébendes à leur nomination ${ }^{14}$. On ne sait si la décision fut suivie d'effet, mais dans l'affirmative, l'existence de la nouvelle collégiale fut des plus courtes.

Les autres collégiales ont eu une existence durable même si leur érection n'est pas toujours allée sans difficultés. L'inventaire qui suit est dressé selon l'ordre chronologique des fondations ou de l'apparition dans les sources (avec renvoi au numéro sur la carte). La première est de fondation comtale. Foulques III Nerra (987-1040), également fondateur du chapitre Saint-Martin d'Angers (entre 1012/1029) et de plusieurs abbayes, institue en 1020 à Blaison (1), au sud de la Loire, un chapitre de 4 chanoines pour desservir l'église Saint-Aubin ${ }^{15}$. Le seigneur de Blaison, premier chanoine, eut de tout temps la présentation des prébendes.

À Doué (5), ancienne résidence carolingienne, la fondation du chapitre Saint-Denis est encombrée d'une tradition appuyée sur un faux diplôme de Dagobert daté de 631 mais forgé au XvI ${ }^{\mathrm{e}}$ siècle; en réalité, la fondation remonte au milieu du $\mathrm{XI}^{\mathrm{e}}$ siècle : une charte-notice de 1063 rap-

11. Cartulaire de l'abbaye Saint-Aubin d'Angers, éd. Bertrand de Broussillon, Paris, 1903 , chartes $n^{\circ} 287$ et $n^{\circ} 306$.

12. Marchegay, Paul, Archives d'Anjou. Recueil de documents et mémoires inédits, Angers, 1848, t. 2, p. 32-35; CARRE DE BuSSEROLle, Jean-Xavier, Dictionnaire géographique, historique et biographique d'Indre-et-Loire et de l'ancienne province de Touraine, Tours, 1883 , t. 3, p. 324-328.

13. Cartulaire noir de la cathédrale d'Angers, éd. Charles Urseau, Paris-Angers, 1908 (désormais abrégé Cartulaire noir), charte $\mathrm{n}^{\circ} 192$.

14. Cartulaire noir, chartes $n^{\circ} 63$ et $n^{\circ} 81$.

15. PORT, Célestin, Dictionnaire historique, géographique et biographique de Maine-etLoire, $2^{\mathrm{e}}$ éd., Angers, 1965-1996, t. 1, p. 375. 
pelle que Gontier, un des seigneurs qui se partageaient avec les prêtres les revenus des églises de Doué, a établi un collège de 4 chanoines - dont son fils - auquel il donna divers biens, dîmes et revenus ${ }^{16}$. À l'inverse de ce qui a été observé auparavant, l'acte précise que les chanoines remplacent les moines du monasterium Sancti Dionisii, ce qui témoigne encore dans ce cas du caractère informel et juridiquement instable de ces communautés au XI ${ }^{\mathrm{e}}$ siècle. Entre 1063 et 1093, les chanoines de Doué se placèrent sous la dépendance et en union de prières avec le chapitre cathédral d'Angers ${ }^{17}$, mais en 1096, le pape Urbain II déclencha un conflit avec les chanoines en concédant à l'abbé de Tournus la nomination des prébendes. L'issue ne fut trouvée qu'en 1129 lorsque Ulger ratifia un accord avec l'abbé : les chanoines concédaient leur église à Tournus, s'engageaient à recevoir parfois l'abbé, et promettaient de déposer un cens annuel sur l'autel du prieuré de Cunaud dépendant de l'abbaye. En échange, l'évêque obtenait à perpétuité la présentation et la collation des prébendes dont le nombre, passé à 8 , était ramené à $6^{18}$.

À Saint-Nicolas de Craon (4), le même Ulger fut cette fois en lutte avec la puissante abbaye de la Trinité de Vendôme. Comme ceux de ChâteauGontier ou de Laval ${ }^{19}$, les barons de Craon ont voulu avoir une collégiale de séculiers près de leur château. Robert le Bourguignon, fils de Renaud de Nevers et de la fille du roi Robert ${ }^{\text {er }}$ Adelaide, fut investi de la seigneurie de Craon par le comte Geoffroi Martel avant 1054. Entre 1078 et 1095, il fonda un chapitre de 6 prébendes pour le service de la cité castrale $^{20}$. Vers 1117 , son petit-fils Hugues ${ }^{\text {er }}$ fit de la collégiale une simple dépendance de l'abbaye de chanoines réguliers de la Roë également fondée par Robert le Bourguignon. La donation fut ratifiée par le pape Pascal II mais contestée par les moines de Vendôme. À la demande d'Ulger, Innocent II régla le problème par une bulle de compromis datée de janvier 1136 : l'évêque obtenait la présentation d'une prébende, l'abbé de Vendôme en avait deux et la Roë conservait les autres ${ }^{21}$. Par la suite, le seigneur de Craon eut tous les droits sur les prébendes - dont le nombre avait été porté à 8 - sauf celle de l'ordinaire.

Les premiers temps du chapitre Saint-Léonard de Chemillé (3) nous remettent en présence de l'abbaye tourangelle de Marmoutier. La Villa de Chemillé, ancienne possession de Saint-Martin de Tours, avait été réunie au domaine de l'évêque d'Angers en 844. Ce dernier l'inféoda à partir du début du XI ${ }^{\mathrm{e}}$ siècle à des seigneurs dont le second, Pierre, fonda le prieuré

16. Arch. dép. du Maine-et-Loire, G 1541, $\mathrm{f}^{\circ} 1$ (faux diplôme), et f ${ }^{\circ} 2$ (charte-notice).

17. Cartulaire noir, charte $\mathrm{n}^{\circ} 118$.

18. Arch. dép. du Maine-et-Loire, G 1541, $\mathrm{f}^{\circ} 6$.

19. Pour Château-Gontier, voir infra. Pour Laval, au diocèse du Mans, voir BoHuon, P. et ERAUd, Dominique, "La collégiale Saint-Tugal de Laval ", La Mayenne. Archéologie, histoire, t. 22, 1999, p. 63-86.

20. Angot, (Abbé), Dictionnaire historique, topographique et biographique de la Mayenne, $2^{\mathrm{e}}$ éd., Laval, 1977, t. 1, p. 812.

21. Cartulaire noir, charte $n^{\circ} 228$; HAMON-JugnEt, Marie, Cartulaire de l'abbaye NotreDame de la Roë. Édition critique, Thèse École des chartes, 1971, charte ${ }^{\circ} 5$. 
Saint-Pierre où il installa des moines venus de Marmoutier vers 1040. Entre 1082 et 1090, Pierre II fit édifier hors de l'enceinte de la ville une nouvelle église dédiée aux saints Léonard et Barthélemy, et y installa des chanoines qui se placèrent comme ceux de Doué sous la tutelle du chapitre cathédral en $1094^{22}$. Un long conflit débuta alors avec Marmoutier qui obtint, sous l'épiscopat de Matthieu de Loudun (1156-1162), la confirmation de sa tutelle sur la collégiale, mais l'évêque avait là aussi réussi à se réserver la présentation des 8 prébendes de chanoines ${ }^{23}$.

Si le bourg de Château-Gontier (2) a été fondé par le comte Foulques III Nerra en 1007, le territoire appartenait à l'abbaye Saint-Aubin d'Angers qui y possédait au début du $\mathrm{XII}^{\mathrm{e}}$ siècle trois des cinq églises ${ }^{24}$. La collégiale Saint-Just, fondée pour desservir la paroisse castrale, semble antérieure à 1080, date à laquelle Helinamnus, canonicus Castri Gunterii apparaît comme témoin dans une charte de Saint-Aubin ${ }^{25}$. En octobre 1145, Alard II, seigneur du lieu et neveu de Renaud le Bourguignon, restitua la collégiale à Ulger en échange d'un service anniversaire dans la cathédrale d'Angers, l'ordinaire du diocèse obtenant par la même occasion le droit de conférer les 4 prébendes du chapitre ${ }^{26}$.

Le chapitre de Martigné-Briand (8) est antérieur aux années 1123/1125, quand l'évêque Renaud de Martigné, fils du seigneur du lieu, lui donna des terres et des revenus pour la célébration des anniversaires des chanoines défunts ${ }^{27}$. On ne sait à quand elle remonte, mais la collégiale, qui devait un cens annuel au chapitre cathédral, est de fondation seigneuriale, confirmée en 1240 puis $1346^{28}$.

La première vague de fondation s'interrompt donc avant le milieu du $\mathrm{XII}^{\mathrm{e}}$ siècle, et elle se présente comme une manifestation de la réforme de l'Église entreprise au siècle précédent. À Angers comme dans le reste du diocèse, l'épiscopat d'Ulger a eu une importance décisive pour le destin de ces chapitres, de sorte que le trait commun que présentent ces collégiales semble bien être la tutelle du pouvoir épiscopal, bien que l'ordinaire n'apparaisse jamais comme fondateur de ces collèges. Cette observation n'est pas démentie par les fondations de la fin du Moyen Âge, pas plus qu'elle ne l'est pour la seule collégiale érigée entre-temps à SaintPierre-Montlimart (10). Il semble que ce soit le seigneur de Bohardy, au Petit-Montrevault, qui obtint l'érection ou la reconnaissance d'une collégiale de 8 chanoines par l'évêque Michel Villoiseau (1240-1261) dans

22. Cartulaire noir, charte $\mathrm{n}^{\circ} 59$.

23. Ibidem, chartes $n^{\circ} 117$ et $n^{\circ} 214$. HeMmer, Henri, Le cartulaire de Saint-Pierre de Chemillé. Édition précédée d'une étude sur le rôle économique et social des prieurés angevins de Marmoutier, Thèse École des chartes, 1944, chartes n ${ }^{\circ} 175$ et 178 . Ce conflit a été étudié par Jean-Marc BIENVENu (cité note 7).

24. En dernier lieu, PECHA, Michel, La châtellenie de Château-Gontier aux XI et XI ${ }^{e}$ siècles, Maîtrise d'histoire, Université d'Angers, 1999.

25. Cartulaire de l'abbaye Saint-Aubin, cité note 10, charte n 165 (ici p. 190).

26. Cartulaire noir, charte $n^{\circ} 206$.

27. Ibidem, charte $\mathrm{n}^{\circ} 112$.

28. Arch. dép. du Maine-et-Loire, G 1334. 
l'église Saint-Pierre qui appartenait au chapitre cathédral ${ }^{29}$. L'intention du châtelain et du prélat - qui se partageaient par moitié la présentation des prébendes - paraît avoir été de contrebalancer l'influence locale de l'abbaye de Saint-Florent [-le-Vieil] et du prieuré Saint-Jean dépendant de l'abbaye Saint-Serge d'Angers.

\section{Les fondations de la fin du Moyen Âge}

La création de collégiales forme en certaines régions - comme en Bourgogne ou dans une moindre mesure en Poitou - un mouvement continu. Il n'en est rien en Anjou. Saint-Pierre-Montlimart mis à part, trois siècles séparent les dernières fondations du XII ${ }^{\mathrm{e}}$ siècle de la timide reprise de la fin du Moyen Âge. Cette nouvelle génération de chapitres provient encore de l'initiative de seigneurs laïques, mais les fondations ne sont pas plus uniformes qu'auparavant.

La Grésille (6) est une ancienne seigneurie passée par mariage au $\mathrm{XV}^{\mathrm{e}}$ siècle aux mains de la puissante famille des Turpin. Comme le montre l'acte de fondation édité en annexe, le chapitre de 5 chanoines, sous la dédicace de Notre-Dame-des-Vertus, est institué en 1455 par Anne de La Grésille pour accomplir la volonté de son père défunt, Geoffroi, ancien seigneur du lieu, et pour le salut de l'âme de son défunt mari, Antoine Turpin, chambellan de Charles VI et Charles VII ${ }^{30}$. La collégiale est établie dans la chapelle castrale jusqu'alors desservie par des chapelains chargés de célébrer les messes fondées par les anciens seigneurs de la Grésille.

Une seconde collégiale aurait pu voir le jour un quart de siècle plus tard, mais la volonté du fondateur ne fut pas respectée. La chapelle NotreDame de Béhuard était alors la destination d'un pèlerinage marial dont le rayonnement dépassait de loin les frontières de l'Anjou. Le roi Louis XI (1461-1483) avait une dévotion particulière à la Vierge de Béhuard; il s'y était voué dès 1453 dans le but d'échapper à la noyade, y fit construire une somptueuse chapelle à la place de l'ancien oratoire, et y parut une vingtaine de fois en pèlerinage ${ }^{31}$ - ce qui lui permettait de surveiller le duché qui devait lui revenir à la mort de son oncle René. L'Anjou réuni à la Couronne de France en 1480, le roi décida l'année suivante d'instituer un chapitre sur l'île de Béhuard qui devenait possession de la collégiale, transformée en paroisse, à laquelle il donnait divers revenus dont le " trespas de Loire ", droit de passage que payaient toutes les marchandises cir-

29. PorT, Célestin, Dictionnaire, cité note 15, t. 4, p. 215.

30. On peut rappeler que de leur mariage célébré en 1427 naquirent 8 enfants dont Pierre (vers 1433-1434), chanoine de la cathédrale d'Angers depuis 1456, puis évêque d'Évreux (1470-1473); voir MATZ, Jean-Michel, « La noblesse angevine et l'Église au temps de la seconde d'Anjou (vers 1356-vers 1480) ", dans CouLET, Noël et MATZ, JeanMichel, (dir.), La noblesse dans les territoires angevins à la fin du Moyen Âge (actes du colloque d'Angers-Saumur, 1998), Rome, 2000 ("Collection EFR », 275), p. 619-637, ici p. 629 .

31. BodaIRE, (Abbé), "Les dévotions de Louis XI en Anjou ", Revue de l'Anjou, 1861, p. 161-182. 
culant entre Saumur et les Ponts-de-Cé ${ }^{32}$. Mais le roi mourut le 30 août 1483 sans que Rome ait ratifié la fondation et avant que la Chambre des comptes ait entériné l'abandon du trépas. Béhuard resta donc une simple chapelle qui bénéficia toutefois des libéralités et des fondations pieuses établies par Louis XI, exécutées par Jean Bourré ${ }^{33}$.

Suivant l'exemple de son souverain protecteur, Jean Bourré, par un acte daté du 9 mars 1500, transforma l'église paroissiale de Jarzé (7) en une collégiale desservie par 5 chanoines $^{34}$. L'homme est bien connu ${ }^{35}$. Né à Château-Gontier en 1424, licencié en lois, il fit toute sa carrière au service de Louis XI qui l'anoblit vers 1465 et le fit trésorier de France et de l'Ordre de Saint-Michel qu'il venait d'instituer ; modèle de fidélité, Bourré continua à servir les successeurs de Louis XI, au Conseil comme à la Chambre des comptes. Seigneur du Plessis-Bourré, de Jarzé, Cheffes-sur-Sarthe, Bourg et Écuillé, il fut un grand bâtisseur jusqu'à sa mort en 1506, après laquelle il fut inhumé dans sa collégiale où ses restes se trouvent encore.

La dernière fondation intervient dans des circonstances particulières dans la mesure où le fondateur dut se résoudre à instituer un chapitre séculier après l'échec d'autres tentatives. Jean III de Chambes († 1519) est le fils de Jean de Chambes, qui s'illustra à la cour de Charles VII et acquit la seigneurie de Montsoreau (9) en 1445, et de Jeanne Chabot, d'une ancienne famille noble, dame d'Argenton. Vers 1490, Jean III épousa Marie de Châteaubriant, fille de René, comte de Casan et baron du Lion d'Angers, et d'Hélène d'Estouteville; Marie était par ailleurs nièce du doyen du chapitre cathédral d'Angers François de Châteaubriant (1516-1535), ce qui explique vraisemblablement les prescriptions détaillées qui figurent dans l'acte de fondation en matière de célébrations liturgiques. Cet acte, daté du 31 mars 1520 (n. s.), rappelle que de son vivant, Jean de Chambes avait voulu fonder " un couvant de l'ordre des freres mineurs des religieux de frere François de Paule et que de faict il avoit commancé avecq ledict de Paule laditte fondation, laquelle fondation lesdicts freres mineurs après le trespas dudict frere François ne voullurent entretenir ne accepter, et après ledict refus derechef s'efforça y fonder un couvant de religieux reformez de l'ordre monsieur sainct Augustin à quoy ne peu parvenir ${ }^{36}$ ". La faveur des religieux mendiants réformés - Minimes comme Ermites de saint Augustin pour le cas présent - dans la noblesse est un fait notable dans les provinces de Touraine, du Poitou et de l'Anjou aux confins desquelles se

32. PORT, Célestin, Dictionnaire, cité note 15, t. 1, p. 324.

33. Arch. dép. du Maine-et-Loire, G 1489, fondations confirmées par Charles VIII contrairement à l'institution du chapitre; le même Jean Bourré fut aussi chargé de mettre en application la fondation par Louis XI d'un chapitre de 13 chanoines au Puy-Notre-Dame, en Anjou mais au diocèse de Poitiers, institué par lettres patentes en janvier 1482 et confirmé par Sixte IV en mars 1483 (Arch. dép. du Maine-et-Loire, G 1488).

34. Arch. dép. du Maine-et-Loire, E 1793 (fondation du chapitre), confirmée par son testament de 1505 et ses codicilles (Arch. dép. du Maine-et-Loire, G 1328).

35. BRICART, Georges, Jean Bourré, seigneur du Plessis (1424-1506), Paris, 1893.

36. Arch. dép. du Maine-et-Loire, G 1465, f 2 (copie de 1676). 
situe Montsoreau ${ }^{37}$, mais Jean de Chambes ne put obtenir leur installation durable dans le château où il avait entrepris une campagne de grands travaux. Il dut se résigner à établir un chapitre séculier comprenant 6 chanoines. La collégiale Sainte-Croix de Montsoreau est la dernière des dix églises de chanoines séculiers ayant eu une existence durable après sa fondation dans le diocèse d'Angers.

\section{Organisation et composition des chapitres}

\section{Institutions et fonctionnement}

Les collégiales fondées dans le diocèse d'Angers représentent au total 60 prébendes, soit une moyenne de 6 par église, mais les effectifs vont de 4 chanoines (Blaison ou Château-Gontier) à 8 au maximum (Chemillé, Craon et Saint-Pierre-Montlimart). Ces effectifs restreints expliquent qu'à la différence des collégiales de la cité d'Angers, les hiérarchies internes restent assez simples et le nombre de dignités limité lorsqu'elles existent, ce qui n'est par exemple pas le cas à Martigné-Briand. Les communautés sont dirigées par un chanoine qui porte des titres variables : doyen (Chemillé, Montsoreau, Saint-Pierre-Montlimart), " chanoine correcteur " - qui est le plus ancien chanoine - à Château-Gontier ${ }^{38}$, il est simplement désigné comme " premier chanoine " à Jarzé où ce titre est réservé au curé de la paroisse, membre de droit depuis la fondation comme à la Grésille. Le chantre, responsable du chant et de la liturgie au chœur, n'est attesté que dans certaines collégiales (Blaison, Doué ou Craon) ${ }^{39}$, bien qu'il devait exister ailleurs dans les faits.

La conservation très inégale de la documentation ne permet pas de connaître avec précision le fonctionnement de toutes les communautés même à la fin du Moyen Âge ${ }^{40}$. Les chanoines semblent se réunir au moins une fois par semaine pour les affaires courantes, et l'absence est en certains cas punie d'une amende, comme à Château-Gontier ou Montsoreau ${ }^{41}$.

37. MATZ, Jean-Michel, « La noblesse angevine et l'Église », cité note 30, p. 631-636.

38. Bibl. mun. Château-Gontier, ms. 9, p. 133 (article 7 des statuts) : Item, in cappitulo, antiquior seu senior canonicorum habebit presidere in factior cappituli loco alterius dignitatis et vocabitur corrector, poteritque corrigere juvenes et aliorum caritative ab excessibuor seu modice inhonestior, tam in modo quam in habitu ne exoriatur scandalum et cetera.

39. Pour les plus anciennes mentions : Blaison (Archivio Segreto Vaticano, abrégé désormais ASV, "Collectories " 257, $\mathrm{f}^{\circ} 49$ ); Doué (ASV, Reg. Lat. 481, $\mathrm{f}^{\circ} 114 \mathrm{v}$, union d'une prébende à l'office de chantre dont les revenus sont insuffisants); Craon (AnGOT, [Abbé], Dictionnaire, cité note 20, t. 1, p. 813).

40. Les informations les plus précises émanent de deux types de sources : les statuts, uniquement conservés pour Saint-Just de Château-Gontier (Bibl. mun. Château-Gontier, ms. 9, p. 131-135, datés de 1414), et les registres de délibérations capitulaires, conservés pour Martigné-Briand (Arch. dép. du Maine-et-Loire, G 1336, à partir de 1498) et Château-Gontier (Arch. dép. Mayenne, 9 G 36, à partir de 1541 mais avec de nombreux rappels d'usages antérieurs).

41. Arch. dép. du Maine-et-Loire, G 1465 (Montsoreau), f ${ }^{\circ}$ 6v : « Item, seront tenus lesdicts six chaplains eux assembler tous les vendredy de l'an entre lesdittes deux messes pour communiquer et adviser entre eux des affaires et divin service de leur ditteeglize, 
Alors que les chanoines des églises d'Angers se réunissent plusieurs fois par an en chapitres généraux, les communautés des villes et des châteaux semblent se contenter de deux assemblées annuelles. À Martigné-Briand, où l'un des deux chapitres généraux se tient à la mi-août, il procède chaque année à la désignation du sacriste de l'église et du procureur des chanoines pour les affaires judiciaires, il entend la reddition des comptes annuels du receveur, et amende ou rappelle éventuellement les statuts auxquels doivent se soumettre les chanoines ${ }^{42}$. Dans les chapitres, outre la gestion du temporel et la désignation des officiers et serviteurs de l'église, les discussions principales portent sur les conditions d'entrée et la résidence des chanoines.

L'entrée dans un chapitre est soumise à des conditions relativement semblables d'une église à l'autre : le nouveau chanoine doit s'engager par serment à respecter les statuts ${ }^{43}$, et il paye ensuite un droit d'entrée - en général une chape destinée à enrichir la collection de vêtements liturgiques - et divers émoluments au personnel de l'église ${ }^{44}$. Il est ensuite astreint à une première résidence continue - de trois mois seulement à Blaison ou Martigné, contre six mois dans les autres collégiales et dans les chapitres d'Angers - pour pouvoir toucher les revenus de son bénéfice. Par la suite, aussi longtemps que dure le canonicat, le chanoine doit respecter l'obligation de la résidence s'il veut percevoir les " gros fruits " de sa prébende et prendre part aux distributions ${ }^{45}$. Les actes de la pratique montrent toutefois la fréquence des dispenses de résidence, notamment pour études ${ }^{46}$, le chanoine dispensé ayant alors à sa charge l'entretien du prêtre recruté pour le suppléer au chœur s'il veut continuer à toucher les fruits de son bénéfice ${ }^{47}$. Dans certains cas, l'absence est sanc-

tant du revenu qu'entretenemants d'icelle [...]. Et à icelle assemblée tous seront tenus comparoir sur peine de cinq deniers tournois pour chacun deffault. "

42. On le voit notamment avec les décisions prises en 1507, 1513, 1523, 1525, 1527 (Arch. dép. du Maine-et-Loire, G 1336, f ${ }^{\circ}$ 15v-16, 27, 60, 64v-65 et 81-82v).

43. Arch. dép. du Maine-et-Loire, G 1465 (Montsoreau), $\mathrm{f}^{\circ}$ 9v : " Item, sera tenu chacun desdicts chapplains ou viccaires promettre et jurer à sa reception entretenir touttes et chacunes les clauses de ceste presente fondation, et à payer et bailler à laditte eglize à sa ditte reception, et avant que pouvoir rien percepvoir des fruicts de sondit benefice, cent solz".

44. À Martigné-Briand, d'après une conclusion du chapitre de 1527 , il doit $10 \mathrm{~s}$ pour sa lettre de réception et 2 royaux d'or pour le sceau du chapitre, $40 \mathrm{~s}$ à chaque desservant du chœur, $5 \mathrm{~s}$ au sacriste pour la sonnerie des cloches et $10 \mathrm{~s}$ pour le bedeau (Arch. dép. du Maine-et-Loire, G 1336, f 82 ).

45. Cette prescription est souvent rappelée par les conciles provinciaux, à Angers en 1366 et 1448 ou à Nantes en 1431 : Les conciles de la province de Tours (XIII $\left.{ }^{e}-X V^{e}\right)$, Paris, éd. Joseph Avril, 1987, p. 383, 427, 447 et 460. La règle est encore évoquée au chapitre de Château-Gontier en 1548 (Arch. départ. Mayenne, 9 G 36, f 8).

46. À Martigné-Briand, en 1508, 3 des 6 chanoines sont dispensés pour cette raison (Arch. dép. du Maine-et-Loire, G 1336, $\mathrm{f}^{\circ}$ 19v).

47. Arch. dép. du Maine-et-Loire, G 1336, f ${ }^{\circ} 60$ : en 1523, les 2 chanoines dispensés doivent chacun 17 l.t. $10 \mathrm{~s}$ à cette fin; même fonctionnement à Château-Gontier (Bibl. mun. Château-Gontier, ms. 9, p. 134, art. 10 des statuts de 1414, qui prévoit que la rémunération du vicaire sera alignée sur celle des chapelains). 
tionnée par des amendes, notamment à Montsoreau, collégiale dans laquelle la non-résidence sans justification pendant un mois rend le bénéfice vacant ${ }^{48}$.

Les contraintes de la résidence pour des chanoines ne menant pas vie commune ont amené les fondateurs ou leurs successeurs à doter les membres des chapitres de maisons canoniales individuelles. Cette pratique se rencontre dès l'institution de Saint-Nicolas de Craon à la fin du $\mathrm{XI}^{\mathrm{e}}$ siècle ${ }^{49}$, et les actes de fondation de la fin du Moyen Âge en témoignent encore ${ }^{50}$. Les maisons sont attachées aux prébendes canoniales ${ }^{51}$, ce qui explique que leur entretien soit à la charge du chanoine titulaire ${ }^{52}$. Ces habitations, attenantes à l'église, finissent par constituer une petite enclave canoniale dans l'espace urbain lorsqu'il s'agit de collégiales établies dans des bourgs ou des villes closes.

Les revenus auxquels peut prétendre un chanoine des bourgs ou des châteaux sont évidemment variables d'une église à l'autre, et en partie proportionnels à l'assiduité relative des individus qui détermine le niveau des distributions à la fin du Moyen Âge, mais il semble que leur montant ne garantissait pas l'aisance et ne permettait pas aux clercs avides de s'en contenter. Les sommes indiquées dans le rôle du vingtième levé par la papauté en 1330 sur les bénéfices ecclésiastiques du diocèse d'Angers en donnent une première preuve (tableau 1) ${ }^{53}$.

Tableau 1 - Les revenus par prébende en 1330

\begin{tabular}{|c|c|c|c|}
\hline Chapitre & $\begin{array}{c}\text { Nombre } \\
\text { de prébendes } \\
\text { mentionnées }\end{array}$ & $\begin{array}{c}\text { Taxation } \\
\text { par prébende }\end{array}$ & $\begin{array}{c}\text { Revenu annuel } \\
\text { par prébende }\end{array}$ \\
\hline Blaison & 4 & $20 \mathrm{~s}$ & 20 l.t. \\
Château-Gontier & 2 & $5 \mathrm{~s}$ & 5 l.t. \\
Chemillé & 2 & 7 et $8 \mathrm{~s}$ & 7 et 8 l.t. \\
Craon & 2 & $70 \mathrm{~s}$ & 10 l.t. \\
Doué & 5 & $10 \mathrm{~s}$ & 7 à 25 l.t. \\
Martigné-Briand & 1 & & 10 l.t. \\
\hline
\end{tabular}

48. Arch. dép. du Maine-et-Loire, G 1465, f ${ }^{\circ} 8-8 \mathrm{v}$.

49. Angot, (Abbé), Dictionaire, cité note 20, t. 1, p. 812.

50 . Voir l'acte de fondation de la Grésille en annexe. Une pratique similaire se rencontre aussi avec la fondation du chapitre de Montreuil-Bellay, en Anjou mais au diocèse de Poitiers, où les maisons sont encore visibles aujourd'hui dans le château (Arch. dép. du Maine-et-Loire, G 1350, fondation des seigneurs de la famille Tancarville).

51. À Blaison, en 1532, les chanoines s'entendent ainsi pour jouir dorénavant de façon séparée de "leurs maisons, jardins, domaines et mestayries appellées les prébendes et prébendelles dudict Blaison " (Arch. dép. du Maine-et-Loire, G 1270).

52. À Montsoreau, les maisons sont mises aux enchères entre les chanoines, et « lesdicts logis et appartemens serront à l'advenir entretenus par ceulx qui les prendroyent en bonnes et suffizantes reparacion " (Arch. dép. du Maine-et-Loire, G 1466).

53. Recueil des historiens de la France. Pouillés. T. 3 : Pouillés de la Province de Tours, éd. Auguste Longnon, Paris, 1903, p. 183-205; les pouillés suivants adoptent une taxation pour l'ensemble du chapitre et des chapelains, et ne sont donc plus utilisables. 
Par la suite, pendant et après les " crises ", les renseignements font pour l'essentiel défaut, à quelques exceptions près : les annates (soit l'équivalent du revenu annuel pour un bénéfice obtenu en Cour de Rome) pour une prébende de Saint-Just de Château-Gontier s'élèvent seulement à 10 l.t. en $1430^{54}$, alors que l'acte de fondation de la Grésille prévoit un revenu annuel de 40 l.t. par prébende en 1455, ce qui ne semble pas avoir été assuré. Le niveau relativement modeste de ces revenus a amené les individus à recourir au cumul des bénéfices pour atteindre un certain niveau d'aisance, et il n'est pas resté sans effet sur le recrutement canonial.

\section{Le recrutement}

Les règles du recrutement sont simples. Conformément au droit canon, l'évêque d'Angers détient la collation des prébendes dans toutes les collégiales de son diocèse, mais il n'en a pas toujours la présentation. Depuis leur restitution à l'ordinaire, le prélat ou ses vicaires peuvent présenter les titulaires de toutes les prébendes de Château-Gontier, Chemillé ou Doué ${ }^{55}$; comme nous l'avons vu, il désigne aussi un chanoine à Craon et la moitié de ceux du chapitre de Saint-Pierre-Montlimart. Les seigneurs fondateurs ont toutefois cherché à se réserver la présentation des chanoines de leurs chapitres, de manière à faire de ces collégiales des réserves de bénéfices permettant de rétribuer des serviteurs ou de placer des enfants ou des proches parents entrés dans la cléricature. Telles sont en principe les règles de base de l'obtention d'une prébende aux derniers siècles du Moyen Âge. Qu'en est-il dans la réalité, et qui sont les chanoines?

Il faut d'abord reconnaître que les sources conservées ne se prêtent pas à une enquête prosopographique systématique, puisqu'il est totalement impossible, encore en fin de période, de reconstituer des listes complètes de chanoines pour une église, et que de nombreux individus restent inconnus en dehors de leur nom - ce qui constitue, par défaut, la preuve d'une notoriété et de perspectives de carrière pour le moins limitées. L'image d'ensemble paraît révéler dans un premier temps un monde globalement assez terne, au recrutement essentiellement indigène et sans grand rayonnement intellectuel ${ }^{56}$, mais socialement assez ouvert.

54. ASV, « Annates » IV, f ${ }^{\circ} 284$.

55. Cartulaire noir, chartes $n^{\circ} 203$ et 206 pour Château-Gontier, et charte $n^{\circ} 214$ pour Chemillé. Pour Doué, Arch. dép. du Maine-et-Loire, G 848, f ${ }^{\circ}$ 1, confirmation par Ulger en juillet 1130 contre les prétentions du prieur de Cunaud.

56. Si nous laissons de côté les chanoines d'Angers pourvus de prébendes dans ces collégiales, les autres individus repérés dans les sources n'appartiennent pas aux élites intellectuelles de l'époque. Les gradués sont très minoritaires, et les testaments de chanoines conservés (une dizaine seulement) ne mentionnent pas de livres, à l'exception de celui de Jean Marchant, chanoine de Doué et recteur de 2 paroisses au diocèse de Poitiers, daté de 1490, qui précise : « Item, je donne touz mes livres, c'est assavoir mon breviaire, ung beau Racionnel, Bible et touz aultres pour estre mys en la librarie comme les aultres livres donnez et leguez par mes predecesseurs, pour estre ès prieres, oraisons et suffraiges de ladicte eglise. Et les aultres livres qui ne sont pas 
Le monde des chanoines des collégiales ne peut toutefois être caricaturé sous les traits d'un groupe uniforme et nivelé vers le bas, et la situation devait différer entre les collégiales urbaines et celles des campagnes. Il importe donc de retrouver les principales catégories d'individus qui composent ce groupe clérical ${ }^{57}$. Sous réserve de confirmation par une étude systématique des sources, nous trouvons trois types de chanoines, inégalement représentés.

À la fin du Moyen Âge, les chapitres semblent se composer en majorité de modestes séculiers qui ont en général débuté leur carrière avec des chapellenies ou des cures et par l'exercice de fonctions religieuses ou temporelles au service des collégiales, et la terminent comme titulaires d'une prébende qui ressemble pour eux à un bâton de maréchal. Les registres de la collégiale de Martigné-Briand en donnent de nombreux cas : Macé Abraham, prêtre, d'abord receveur du chapitre, y devient chanoine avant 1460 et le reste jusqu'à sa mort vers 1486, sans qu'on lui connaisse d'autre bénéfice ${ }^{58}$; plus tard, Jacques Trésor, après avoir détenu plusieurs chapellenies à Martigné et dans les paroisses voisines, décroche lui aussi une prébende (1520-1548) dans laquelle lui succèdera son neveu Jacques Trésor le jeune ${ }^{59}$. D'autres exemples de succession d'oncle à neveu montrent que les stratégies des familles roturières peuvent contribuer à conforter ces situations acquises, comme à Saint-Just de Château-Gontier et Craon et peut-être dans d'autres collégiales urbaines ${ }^{60}$.

Les solidarités lignagères et les relations de clientèle sont encore plus évidentes dans la noblesse angevine où les familles écuyères usent de leurs réseaux d'alliances pour placer des hommes dans les collégiales. À la fin du Xve et au début du XvI ${ }^{\mathrm{e}}$ siècle, René de La Jumellière, seigneur de la Guerche, du Vieil-Baugé et de Martigné-Briand, baron de Blaison, exerce avec fermeté son droit de présentation aux prébendes des deux collégiales qu'il tient par droit de succession ${ }^{61}$. Il introduit ainsi dans les

à moy, je vieil qu'ilz soient renduz et restituez à ceulx à qui ilz appartiennent " (Arch. dép. du Maine-et-Loire, G 1561, pièce 201).

57. Pour le cadre général de ce milieu clérical et pour la critique d'une vision trop réductrice, voir Le clergé rural dans l'Europe médiévale et moderne (Colloque de Flaran, XIII), éd. Pierre Bonnassie, Toulouse, 1995, et dans le cas des campagnes angevines, MATz, Jean-Michel, "Chapellenies et chapelains dans le diocèse d'Angers (13501550) : éléments d'enquête ", Revue d'Histoire ecclésiastique, t. 91, 1996, p. 371-397.

58. Arch. dép. du Maine-et-Loire, G 1343 et G 1347.

59. Arch. dép. du Maine-et-Loire, G 1336, f ${ }^{\circ} 51 v$ et 150 pour les dates extrêmes de son canonicat; pour ses autres bénéfices, G 1344, G 2124 et G 2200.

60. Arch. dép. Mayenne, 9 G 36, f ${ }^{\circ}$ 6-7, entre François et Jean Gannaing en 1546, et entre Mathurin et François Grimoust en 1548 (alors qu'un Christophe Grimoust est chanoine dès 1542). L'absence d'études historiques portant sur la société des petites villes de l'Anjou nous empêche de vérifier l'hypothèse d'un recrutement au moins partiel des chanoines dans les rangs de la petite bourgeoisie ou des élites marchandes.

61 . René, qui siège plusieurs fois en chapitre au milieu des chanoines, revendique encore son droit de présentation en 1518: «Laquelle prebende et chanoinie de Sainct-Simplicien, touteffoiz et quantes qu'elle vacque par mort, resignation, permutation ou autrement en quelque maniere que ce soit, la collacion, provision, institution et totalle autre disposition nous appartient de nostre plain droict " (Arch. dép. du Maine-et-Loire, G 1336, $\mathrm{f}^{\circ} 48 \mathrm{v}$ ). 
chapitres des rejetons de lignages qui lui doivent hommage : à Blaison, Gilles et François d'Aubigné, le second étant aussi chapelain à MartignéBriand $^{62}$; dans cette autre collégiale, les chanoines nobles sont plus nombreux, et l'on trouve parmi eux Jean de La Jumellière, fils du patron de l'église, chanoine en 1506 et aussitôt dispensé de résidence per certis causis $^{63}$. La famille de Chambes agit à l'identique pour la présentation des prébendes et des chapellenies fondées à Sainte-Croix de Montsoreau ${ }^{64}$, de sorte que la petite noblesse est bien représentée dans les chapitres.

Les prérogatives épiscopales ont également permis à certains ecclésiastiques de meilleur rang d'entrer dans les collégiales, mais ils restent minoritaires. Des membres de la curie épiscopale ou des chanoines d'Angers pouvaient ainsi obtenir une source supplémentaire de revenus, et servir à l'occasion de relais au gouvernement épiscopal, à condition de passer de temps en temps dans la collégiale. Le chapitre SaintLéonard de Chemillé a eu plusieurs doyens issus du service d'un prélat : Thomas Lepot, jusqu'à sa mort en $1448^{65}$, auquel succède dans la seconde moitié du $\mathrm{XV}^{\mathrm{e}}$ siècle un noble angevin, Gui Pierres, réputé pour son avidité ${ }^{66}$. La situation n'est pas propre à Chemillé et elle se retrouve ponctuellement dès le XIV ${ }^{\mathrm{e}}$ siècle comme à Saint-Pierre-Montlimart où le doyen de la cathédrale d'Angers, Jean de Cherbée, est accessoirement chanoine ${ }^{67}$. Les sources ne permettent pas d'apprécier leur présence effective, que la prébende ait été tenue en début ou en fin de carrière, mais il est évident que le cumul de bénéfices et de charges n'encourageait pas à une exacte résidence. Les clercs pourvus par provision pontificale n'étaient pas forcément plus assidus. Ils semblent d'ailleurs rela-

62. Arch. dép. du Maine-et-Loire, G 1270 et G 1271.

63. Arch. dép. du Maine-et-Loire, G $1336, \mathrm{f}^{\circ} 14 \mathrm{v}$ pour Jean de La Jumellière. Des prébendes sont tenues par Jean de La Brunetière (1499-1515), également curé de la paroisse de la Jumellière, non-résident dans sa prébende et privé des gros fruits en 1513 avant sa résignation; Jean de Maligné (1505-1518), par ailleurs titulaire de plusieurs chapellenies; Antoine de Charnacé, bachelier en décrets et aussi chanoine de Blaison, ou plus tôt René de Pontlevoy (1476-1488) issu d'une famille fieffée à Martigné (Arch. dép. du Maine-et-Loire, G 1336 et G 1347 pour tous ces individus).

64. Arch. dép. du Maine-et-Loire, E 1921.

65. Licencié en décrets, prêtre originaire du diocèse de Bayeux où il rencontra le futur évêque Jean Michel (1439-1447) qui y était alors chanoine, il fut d'abord recteur de diverses paroisses (Bauné, Champteussé, et Saint-Hermeland au diocèse de Nantes), puis notaire épiscopal, greffier de l'officialité, enfin chanoine de Saint-Maimbeuf d'Angers (1441-1448) et doyen de Chemillé, son plus haut titre (ASV, " Annates " IV, f 191 ; Arch. dép. du Maine-et-Loire, G 334, G 694 et G 758; Bibl. mun. Angers, ms. 727 [657], $\left.\mathrm{f}^{\circ} 76\right)$.

66. Docteur dans les deux droits, chanoine de Saint-Martin de Tours et de Saint-Pierre d'Angers, chanoine de la cathédrale (1466- $\dagger$ 1512) où il est aussi maître-école et vicaire de l'évêque; pour Gui Pierres, je renvoie par anticipation à la notice et aux sources le concernant dans Fasti Ecclesiae Gallicanae, cité note 1, à paraître.

67. Jean de Cherbée est prébendé des cathédrales de Saint-Malo, Nantes, Tours et Angers où il tient aussi le décanat (1380-1412), et par ailleurs conseiller des ducs d'Anjou et professeur régent en droit à l'Université d'Angers ; pour les sources, même remarque que pour Gui Pierres à la note précédente. 
tivement peu nombreux, car les revenus d'une prébende dans une collégiale ne la plaçaient pas en haut de l'échelle des bénéfices que les curialistes d'Avignon au XIV et de Rome au XV ${ }^{\mathrm{e}}$ siècle étaient tentés d'obtenir en priorité pour augmenter leurs ressources ${ }^{68}$. Présents au moins sur le papier, ces carriéristes contribuent donc à diversifier encore la composition des collèges, mais ces pratiques ont eu des conséquences sur la vie interne des chapitres.

\section{Les collégiales dans la société}

\section{Fonctions religieuses}

Quelle que soit la date d'institution de ces collégiales, elles sont - comme tout établissement séculier - soumises au pouvoir épiscopal. L'institution d'un chapitre et toute réglementation nouvelle de la vie des chanoines doit recevoir l'approbation de l'évêque. Les collégiales sont tenues de participer aux synodes diocésains et aux conciles ${ }^{69}$, de même qu'elles doivent se plier aux visites pastorales de l'ordinaire ou du métropolitain de Tours ${ }^{70}$.

Les fonctions religieuses que remplissent les collégiales peuvent varier d'une église à l'autres car elles découlent des finalités définies par les seigneurs : l'augmentation du culte divin et le salut de l'âme des fondateurs et de leurs parents sont des objectifs spirituels partagés par tous les nobles qui ont institué des chapitres séculiers, mais pour certaines collégiales desservies en milieu urbain, la volonté éventuelle de structurer un centre d'habitat et d'y organiser la desserte paroissiale - donc une part du clergé local - ne sont pas à négliger. De ce fait, les églises ont de

68. Des exemples de provisions pontificales se rencontrent dans les Lettres communes des papes d'Avignon éditées tout au long du Xx $\mathrm{x}^{\mathrm{e}}$ siècle par l'École française de Rome et qui mériteraient une étude systématique (pour les pontificats de Jean XXII, Benoît XII, Urbain V et Grégoire XI), et dans les sources manuscrites pour les collégiales de Doué (ASV, "Collectories " 255, $\mathrm{f}^{\circ}$ 13v), de Blaison pour la chantrerie en 1362 et 1443 (ASV, "Collectories " 257, $\mathrm{f}^{\circ} 49$, et " Annates " IX, $\mathrm{f}^{\circ}$ 157v), ou de Chemillé (ASV, "Annates " VII, $\mathrm{f}^{\circ}$ 43). Passé le début du $\mathrm{XV}^{\mathrm{e}}$ siècle, elles semblent se raréfier même si l'on rencontre encore des cas tel Guillaume Chaignon : chapelain de la cathédrale et de la collégiale Saint-Martin d'Angers, curé de Saint-Jean de Château-Gontier et chanoine de Doué en 1430, il succède à Jean d'Hierrain - promu évêque (1439-1449) - dans sa prébende de la cathédrale du Mans, et devient ensuite archidiacre de Laval dans le même diocèse alors qu'il réside régulièrement à Rome sous les pontificats d'Eugène IV (1431-1447) et de Nicolas V (1447-1455) : voir ASV, “ Annates » III (f $\left.f^{\circ} 291 v\right)$, IV (f ${ }^{\circ} 257,282$ et 284v), VIII (f ${ }^{\circ}$ 43v), et Reg. Lat. $463, \mathrm{f}^{\circ} 302$.

69. Obligation rappelée aux conciles de Saumur (1276 et 1294), Angers (1279 et 1292), Château-Gontier (1336) ou Nantes (1431) : Les conciles, éd. Joseph Avril, cité note 45, passim. En 1521, les chanoines de Montsoreau signent une convention avec l'archidiacre d'Outre-Loire relative à l'obligation de figurer aux synodes (Arch. dép. du Maine-etLoire, G 1465).

70. En 1392, la collégiale de Doué est ainsi visitée par l'administrateur de l'archevêché de Tours Séguin d'Auton, également patriarche d'Antioche (Arch. dép. du Maineet-Loire, G 1541, $\mathrm{f}^{\circ} 10$ ). 
multiples fonctions religieuses, mais seule la fonction paroissiale a donné lieu à d'importantes variations.

Par la volonté de leurs fondateurs, les collégiales sont un lieu de récitation immuable de l'office divin où l'on célèbre, d'après l'acte de fondation de Montsoreau, "à haulte voix chacun jour toultes les heures cannoniales, c'est assavoir matine, prime, tierce, sexte, nonne, vespres et complyes selon l'usage dudict diocese d'Angers ${ }^{71}$ ". Dans la pratique, la récitation de l'office a été amendée dans le sens d'une réduction des obligations puisque la résidence est calculée sur la présence à trois des heures seulement ${ }^{72}$, et les chapitres ont prévu les conditions de remplacement des chanoines dispensés de résidence; la non-résidence semble suffisamment développée pour que les actes de fondation de la fin du Moyen Âge prévoient d'entrée de jeu l'institution de " choraux " et d'enfants de chœur en plus des prébendés ${ }^{73}$. Au quotidien, la célébration de l'office incombait donc à ce clergé secondaire qui était aussi chargé du service des fondations.

La dimension funéraire et commémorative est une dimension essentielle de la vie des collégiales pour la caste des fondateurs ${ }^{74}$. L'élection de sépulture dans une église émane bien entendu des seigneurs du lieu - descendants plus ou moins directs des fondateurs - et des familles écuyères qui leur sont liées ${ }^{75}$, ou des chanoines et du clergé de l'église ${ }^{76}$. Les fondations d'anniversaires ou de chapellenies qui accompagnent presque naturellement les sépultures relèvent des mêmes milieux auxquels se joignent quelques laïcs suffisamment riches, de sorte que les collégiales comptent souvent parmi les églises les mieux dotées en bénéfices perpétuels desservis par des chapelains ${ }^{77}$. Comme dans les collégiales d'Angers, ces derniers

71. Arch. dép. du Maine-et-Loire, G 1465, $\mathrm{f}^{\circ} 5$.

72. Bibl. mun. Château-Gontier, ms. 9, p. 132, statut 1 (...et maxime in primis vesperis, matutinis et missa); le statut 9 rappelle aussi l'obligation d'être à l'office en entier, et le texte latin se termine ainsi : " Et n'aillent faire du cul au banc en faisant un vidisse" (?).

73. Outre l'acte de fondation de la Grésille en annexe, Jean Bourré institue à Jarzé 2 chapelains et 2 enfants de chœur en 1500 (Arch. dép. du Maine-et-Loire, E 1793).

74. L'acte de fondation de Montsoreau (Arch. dép. du Maine-et-Loire, G 1465, $\mathrm{f}^{\circ}$ 3v) prévoit même une clause particulière : "A eté ediffyé laditte nouvelle eglize Sainte Croix plus grande et magnifique et en lieu mieux convenable, estante mesme dedans les preclozures dudict chasteau et proche laditte ancienne qui est très petitte [...], en laquelle ancienne eglize y a plusieurs corps ensepulturez [...], lesquelz corps dessusdicts declarez suplions et entendons estres translattez d'icelle ancienne eglize à Sainte Croix ".

75. Parmi les nombreux exemples, Jean Fleury, écuyer et seigneur de la Galopinière, demande son inhumation à la Grésille et donne 10 l.t. pour la réparation d'un vitrail " afin que mes armes y soient mises en telz endroiz qu'il plaira à mondit seigneur de la Grésille " (Arch. dép. du Maine-et-Loire, G 1325, testament de 1486 n.s.).

76. Par exemple, pour les chanoines de Doué Nicolas Augustin en 1333 (Arch. dép. du Maine-et-Loire, G 340) ou Jean Marchant en 1490 (Arch. dép. du Maine-et-Loire, G 1561, pièce 201). À Blaison, on relèvera le testament du chanoine Guillaume Bondigneau, en 1544, qui demande : «Item, je veux mon corps estre mis en un cercueil en sorte que l'on voye mon visage decouvert " (Arch. dép. du Maine-et-Loire, E 1732).

77. Au milieu du $\mathrm{XVI}^{\mathrm{e}}$ siècle, on dénombre ainsi 23 chapellenies dans la collégiale de Craon et 12 à Château-Gontier (Arch. dép. Mayenne, respectivement 23 G 1 et 2, ou 
sont dirigés par un maire-chapelain dont les obligations - notamment la résidence impérative - sont soigneusement consignées par les chanoines ${ }^{78}$.

Le service divin et les messes pour les défunts représentent la principale responsabilité du clergé des collégiales, mais ce dernier n'est pas toujours absent de l'encadrement paroissial. Les relations entretenues par les chapitres avec l'institution paroissiale n'ont jamais reposé sur une solution commune. Plusieurs églises issues de la première vague de fondations ont été le siège d'une paroisse : Blaison, Château-Gontier et Martigné dès les origines, ou Chemillé qui obtint ce statut à partir de 1316; dans ces collégiales, le desservant n'était pas membre du chapitre, et la fin du Moyen Âge fut marquée par de nombreux conflits nés de l'exercice conflictuel dans un même édifice des prérogatives propres à chacune des institutions qui y étaient établies ${ }^{79}$. À Doué, la situation n'est pas plus simple puisque la desserte paroissiale était en principe fixée à l'église Saint-Pierre, mais le titulaire étant dans ce cas un chanoine de Saint-Denis, il affermait la cure à un vicaire pendant que mariages et baptêmes étaient administrés dans la collégiale ou dans la chapelle attenante dédiée à saint Jean ${ }^{80}$; plusieurs fois, ce fonctionnement a permis au chapitre de Doué d'obtenir l'union de la paroisse à la mense capitulaire pour en annexer les revenus ${ }^{81}$. En revanche, les églises collégiales de Saint-Pierre-Montlimart et de Craon n'ont pas accédé au rang de paroisse dans la période qui nous intéresse ${ }^{82}$. Les fondations de la fin du Moyen Âge n'ont pas davantage été soumises à un régime commun : la collégiale de la Grésille est érigée dans la chapelle du château situé sur la paroisse d'Ambillou et celle de Jarzé dans l'église paroissiale, mais dans les deux cas, le curé est le premier chanoine du chapitre $^{83}$; pour les collégiales tardives, la situation la plus confuse se ren-

17 G 1, 9 G 27 et 9 G 37), 15 à Doué (Arch. dép. du Maine-et-Loire, G 1579 à 1585), ou 10 à Martigné (Arch. dép. du Maine-et-Loire, G 1336 et G 1343-1344).

78. Un maire-chapelain est par exemple mentionné à Blaison (Arch. dép. du Maineet-Loire, E 1732), à Martigné (Arch. dép. du Maine-et-Loire, G 1336), à Château-Gontier (Arch. dép. Mayenne, $11 \mathrm{G} \mathrm{1,} \mathrm{avec} \mathrm{réglementation} \mathrm{de} \mathrm{ses} \mathrm{charges} \mathrm{et} \mathrm{obligations)} \mathrm{ou} \mathrm{à}$ Craon (Arch. dép. Mayenne, 23 G 1, f $5 \mathrm{v}$ ).

79. Le 31 juillet 1492, un accord est conclu entre les chanoines et le curé de Martigné au sujet d'usages négligés par les deux parties; le texte précise aussi : "Item, ledit curé ne dira en son prosne aucune chose qui porte dommaige ou deshonneur ausdits chanoines, aussi lesdits chanoines ne diront ne prononceront aucun dommaige audit curé " (Arch. dép. du Maine-et-Loire, G 1334).

80. Cette situation prévaut encore à l'époque moderne (Arch. dép. du Maine-et-Loire, G 1542).

81. Une telle union a été décrétée en 1453 (VAuCELLE, Edmond-René, Catalogue des lettres de Nicolas $v$ concernant la province ecclésiastique de Tours, d'après les registres des archives vaticanes, Paris, 1908, $\mathrm{n}^{\circ}$ 1227), et en 1500 (Arch. dép. du Maine-et-Loire, G 1541, $\mathrm{f}^{\circ} 34-38$, copie de la lettre d'Alexandre VI datée du 6 octobre).

82. Si la collégiale de Craon n'est devenue paroisse qu'au XIX ${ }^{\mathrm{e}}$ siècle, le chapitre détenait la collation de paroisses aux alentours (Ballots, Denazé, Saint-Michel-du-Bois) depuis une confirmation par l'évêque Raoul de Beaumont en 1196 (Bibl. nat. de France, Fonds Housseau V, $\mathrm{n}^{\circ}$ 2084).

83. Il faut relever que dans les procédures judiciaires qui opposent l'église de Jarzé à d'autres parties, le curé " premier chanoine " apparaît toujours seul, en 1515 pour un 
contre à Montsoreau où des lendemains de la fondation en 1520 jusqu'au $\mathrm{XVIII}^{\mathrm{e}}$ siècle, le chapitre Sainte-Croix et le curé de Saint-Pierre-de-Rest n'ont eu de cesse de se disputer l'administration des sacrements qui était à la fois le signe manifeste d'une émancipation et une source de revenus ${ }^{84}$.

Les collégiales constituent également des pôles de dévotion. La possession de reliques et les pèlerinages qu'elles attirent sont une première voie pour drainer les faveurs des fidèles. Si l'on vénère ainsi saint Léger à Doué ou diverses reliques offertes à Saint-Nicolas par Maurice II de Craon († 1196) à son retour de croisade ${ }^{85}$, Saint-Just de Château-Gontier est alors célèbre pour une portion de la Vraie Croix et la portion d'un bras de saint Just dont le reliquaire fut richement refait par un orfèvre local au $\mathrm{XV}^{\mathrm{e}}$ siècle $^{86}$, pendant que le chapitre de Chemillé s'enorgueillit de sa relique de la Sainte Larme versée par le Christ sur le tombeau de Lazare ${ }^{87}$. Plusieurs collégiales sont par ailleurs le siège de confréries (Doué, ChâteauGontier) ${ }^{88}$, la mieux documentée étant la confrérie Saint-Nicolas établie dans l'église qui lui était dédiée à Craon, institution à la fois religieuse et civile à laquelle adhéraient une bonne part de la noblesse du Craonnais et les élites urbaines, dont les premiers statuts furent rédigés avant $1382^{89}$.

Cet éventail de fonctions confère aux collégiales un rôle de premier plan dans la vie religieuse. Présents et actifs dans la société, les chapitres ont encore en certains cas une prérogative d'importance avec la désignation des maîtres des écoles, à Doué ou à Martigné ${ }^{90}$. La détermination du chapitre de Château-Gontier à défendre son droit de nomination aux écoles contre les prétentions du duc d'Alençon en 1414 témoigne de l'attachement des chanoines à ce domaine d'intervention dans la société ${ }^{91}$.

conflit de dîmes avec le chapitre cathédral (Arch. dép. du Maine-et-Loire, G 352) comme en 1521 pour le partage des offrandes avec la fabrique (Arch. dép. du Maine-et-Loire, G 2069).

84. Arch. dép. du Maine-et-Loire, G 1465 et G 1468 (notamment une enquête testimoniale de 1529-1531 où les chanoines font défiler des témoins qui attestent les avoir vus administrer baptêmes, mariages et extrême-onctions).

85 Angot, (Abbé), Dictionnaire, cité note 20, p. 813.

86. ChARLES, Robert, Notice archéologique sur les monuments de Château-Gontier, ParisLe Mans, 1878, p. 32-33.

87. FillaudeAu, Abbé, Notice historique sur la Sainte Larme de Chemillé, Angers, 1889, qui prétend que la relique de Chemillé serait une portion de celle de l'abbaye de Vendôme.

88. Confrérie Saint-Denis à Doué (Arch. dép. du Maine-et-Loire, G 1560, pièce 149), et Saint-Nicolas à Saint-Just de Château-Gontier (Bibl. mun. Château-Gontier, ms. 9, p. 120).

89. Les statuts furent révisés et complétés en 1537 (Arch. dép. Mayenne, 21 G 1); la confrérie avait fondé pas moins de 7 chapellenies dans la collégiale.

90. Pour Doué, Port, Célestin, Dictionnaire, cité note 15, t. 2; p. 61 ; pour Martigné, Arch. dép. du Maine-et-Loire, G 1336, f 80 (en 1527) ou f 92 (en 1529), avec la désignation d'un rector et eruditor puerorum totius parrochie de Martigneo Briandi.

91. Bibl. mun. Château-Gontier, ms. 9, p. 27-28, sentence du $1^{\text {er }}$ février 1414 n.s. : "Comme les chanoines du college de la chapelle de Saint Just fondée ou chastel de Chasteau Gontier dissent et maintinssent qu'à cause de leurdite fondation et autrement, deument competent et appartient seuls et pour le tout le droit de donner les 


\section{Le temporel et les revenus des collégiales}

Si les collégiales sont ouvertes sur le milieu qui les environne au plan religieux, elles sont aussi un acteur de premier plan dans la vie économique des campagnes et des villes du diocèse d'Angers. Depuis le XI ${ }^{\mathrm{e}}$ siècle, les fondateurs et leurs successeurs ont doté leurs collégiales de biens (terres, vignes, moulins, maisons) et de droits - notamment des dîmes destinés à garantir l'autonomie financière et les besoins quotidiens des établissements que des concessions tardives ont encore enrichis ${ }^{92}$. De même, les actes de fondation de la fin du Moyen Âge énumèrent en détail les différentes composantes de la dotation initiale des collégiales; Montsoreau reçoit ainsi 2 jardins, 20 boisselées de terres et des vignes, 50 l.t. de rentes sur diverses terres, 70 setiers de grains en dîmes, et le fief de la Suze " tant en justice basse et moyenne, cents, rentes de bleds et d'argeant, que en terres labourables, vignes, prez, eaux, pastureaux et autres domaines ${ }^{93}$ ".

Aux revenus du temporel, les chapitres ajoutent encore les ressources tirées des prestations liturgiques, des messes funéraires ou des fondations perpétuelles. Faute de documents, il est néanmoins impossible d'apprécier la part respective des différentes sources de revenus d'une collégiale. La décime levée en 1467 permet seulement d'établir - pour les 8 collégiales existant alors - une hiérarchie des établissements suivant leur assise financière, bien que les sommes indiquées pour la taxation englobent à la fois les ressources des chapitres et celles des chapelains ${ }^{94}$.

Il apparaît que les collégiales les plus prospères sont situées en général dans les villes les plus importantes par leur population et leurs activités, comme Craon - ville d'industrie textile et de foires et grand marché aux bestiaux ${ }^{95}$ - ou Doué, le plus gros marché aux grains du Sud de la Loire ${ }^{96}$. Dans certains cas, le classement des églises ne reproduit toutefois pas ce que l'on pense avoir été la hiérarchie urbaine de l'époque, comme le montre la collégiale Saint-Léonard de Chemillé, située dans la

escolles de grammaire dudit lieu de Chasteau Gontier toutes fois et quantes qu'elles estoient vacantes ou autrement, et en avoient joui et usé par temps suffisant et valable au veu et sceu des officiers dudit lieu de Chasteau Gontier et de tous autres sans aucune contradition ou empeschement..."

92. Par exemple, à Martigné-Briand, Lépart de La Jumellière, seigneur du lieu, donne au chapitre la sixième partie des dîmes qu'il lève sur le fief de Maligné (Arch. dép. du Maine-et-Loire, G 1334, acte du 8 février 1482).

93. Arch. dép. du Maine-et-Loire, G 1465, f ${ }^{\circ}$ 10-10v; voir aussi l'acte de fondation de la Grésille en annexe.

94. Recueil des historiens de la France. Pouillés, cité note 53, p. 225-242. Un rôle de décime est conservé pour l'archidiaconé d'Angers en 1501, auquel appartient une seule collégiale, Jarzé, fondée l'année précédente : la cure est taxée 6 l.t., comme le chapitre (Arch. dép. du Maine-et-Loire, G 17, $\mathrm{f}^{\circ}$ 3v).

95. CinTRE, René, «Activités économiques dans les Marches de Bretagne aux XIV et $\mathrm{XV}^{\mathrm{e}}$ siècles ", Annales de Bretagne et des Pays de l'Ouest, t. 101, 1994, p. 7-36.

96. Le Ment, Michel, Les campagnes angevines à la fin du Moyen Âge. Étude économique (v. 1350-v. 1530), Nantes, 1982, p. 278. 
plus grande ville du Sud-Ouest du diocèse, mais dont la dotation et les ressources restaient limitées ${ }^{97}$.

Tableau 2 - La décime de 1467 sur les collégiales

\begin{tabular}{|c|c|c|}
\hline $\begin{array}{c}\text { Collégiale (et nombre } \\
\text { de prébendes) }\end{array}$ & Montant de la décime & $\begin{array}{c}\text { Montant supposé } \\
\text { des revenus }\end{array}$ \\
\hline Blaison (4) & 12 l.t. & 120 l.t. \\
Château-Gontier (4) & 7 l.t. 10 s & 75 l.t. \\
Chemillé (8) & 12 l.t. & 120 l.t. \\
Craon (8) & 25 l.t. & 250 l.t. \\
Doué (6) & 20 l.t. & 200 l.t. \\
La Grésille (5) & 10 l.t. & 100 l.t. \\
Martigné-Briand (4) & 20 l.t. & 200 l.t. \\
Saint-Pierre- & 12 l.t. $10 \mathrm{~s}$ & 125 l.t. \\
Montlimart (8) & & \\
\hline
\end{tabular}

L'économie des collégiales paraît révéler un contraste important entre les églises d'Angers et celles du reste du diocèse. À Angers, les chapitres ont bien sûr des possessions foncières et des droits dans les campagnes, mais leurs revenus, principalement assurés par le temporel urbain et l'" économie de la mort ", sont surtout perçus en numéraire. La monétarisation des revenus des collégiales des campagnes semble nettement moins avancée. Les comptes du receveur de la collégiale de MartignéBriand ${ }^{98}$ - les seuls conservés! - témoignent de la prédominance très nette des denrées agricoles dans les revenus du temporel de cette église (tableau 3). Les chapitres prélèvent donc des produits, le vin et les blés principalement, qu'ils commercialisent ensuite en partie pour disposer de numéraire, et il ne semble pas qu'ils aient procédé à une conversion massive des prélèvements en nature en ressources monétaires fixes. Il est évident qu'un tel fonctionnement exposait les collégiales des campagnes aux aléas de la conjoncture agricole, même si l'on peut supposer que les chapitres des villes importantes du diocèse devaient avoir des revenus en nature et en argent plus équilibrés.

97. Ce que montre encore, à défaut de sources médiévales, la documentation moderne (Arch. dép. du Maine-et-Loire, G 1604).

98. Arch. dép. du Maine-et-Loire, G 1347; les comptes sont tenus pour 1 ou 2 ans (voire 3 ans pour le dernier), à partir de la fête de l'" Angevine " (Nativité de la Vierge, le 8 septembre); le setier de Martigné, composé de 10 boisseaux, est légèrement supérieur à 110 litres de grains (LE MENE, Michel, Les campagnes angevines, cité note 96, p. 36-48); le prix d'un boisseau se situe au-dessus de $2 \mathrm{~s}$ à la fin du $\mathrm{XV}^{\mathrm{e}}$ siècle. 
Tableau 3 - Les comptes de la collégiale de Martigné-Briand (1432-1492)

\begin{tabular}{|c|c|c|c|c|}
\hline Exercice & $\begin{array}{c}\text { Recettes } \\
\text { en argent }\end{array}$ & $\begin{array}{c}\text { Recettes en } \\
\text { nature (grains) }\end{array}$ & $\begin{array}{c}\text { Dépenses } \\
\text { en argent }\end{array}$ & $\begin{array}{c}\text { Dépenses } \\
\text { en nature }\end{array}$ \\
\hline $1432-1433$ & 15 l.t. 15 s 4 d. & 62,9 setiers & 6 l.t. 5 s 1 d. & $?$ \\
$1450-1451$ & 15 l.t. 9 s 6 d. & 78,1 setiers & $?$ & $?$ \\
$1461-1462$ & 22 l.t. 12 s 8 d. & 80,1 setiers & 21 l.t. 8 s & 19,1 setiers \\
$1466-1467$ & 24 l.t. 12 s 8 d. & 82,7 setiers & 9 l.t. 18 s 4 d. & 8,5 setiers \\
$1467-1469$ & 49 l.t. 5 s 5 d. & 175,3 setiers & 42 l.t. 13 s 1 d. & 19,3 setiers \\
$1469-1471$ & 55 l.t. 6 s & 169,3 setiers & 44 l.t. 9 s 4 d. & 33,7 setiers \\
$1475-1476$ & 29 l.t. 8 d. & 87,4 setiers & 22 l.t. 8 s 7 d. & 20,3 setiers \\
$1476-1477$ & 15 l.t. 8 d. & 75 setiers & 15 l.t. 13 s 8 d. & $?$ \\
$1487-1488$ & 17 l.t. 8 s 2 d. & $?$ & 16 l.t. 11 s 5 d. & $?$ \\
$1488-1489$ & 17 l.t. 8 s 2 d. & 80,6 setiers & 15 l.t. 7 s & $?$ \\
$1489-1492$ & 52 l.t. 4 s 7 d. & $?$ & 48 l.t. 9 s 1 d. & $?$ \\
\hline
\end{tabular}

\section{Conclusion}

Si la plupart des collégiales sont nées de la territorialisation du pouvoir et de la volonté de certains seigneurs de faire rayonner leurs domaines en y établissant un chapitre de chanoines présent dans la société, l'étude de l'ancien diocèse d'Angers montre qu'il n'y a pas de lien systématique entre le niveau de développement urbain et la présence de collégiales. À Saumur, la seconde ville de l'Anjou par sa population, aucune église n'a vu l'institution d'un collège de chanoines, pas plus que d'autres villes closes dont le seuil démographique n'était pourtant pas inférieur à des bourgs dotés d'un chapitre - je pense en particulier à Durtal, Baugé ou La Flèche.

À défaut de se distinguer par leur zèle ou leur ardeur personnelle à célébrer l'office divin, les chanoines des collégiales sont des acteurs importants dans la vie d'un diocèse, et leur situation permet de souligner le caractère profondément inégalitaire de la répartition des revenus à travers le système bénéficial. Les études ou le cumul de charges et de bénéfices dispensent de nombreux chanoines de résider effectivement dans leur église, mais ils perçoivent tout de même les revenus de leur prébende pendant que leurs vicaires, sur lesquels repose jour et nuit la célébration de l'office, doivent se contenter d'une rémunération modique. Alors que le recrutement clérical et sacerdotal reste élevé ${ }^{99}$, ce système de délégation présente toutefois l'avantage d'éponger une partie des effectifs massifs de clercs ou de prêtres en attente de bénéfices même modestes.

L'étude des collégiales séculières permet donc d'enrichir la connaissance que nous avons du monde clérical et du fonctionnement de l'institution ecclésiale, mais elle est également un indicateur précieux de l'his-

99. Voir les registres d'ordination du diocèse : Arch. dép. du Maine-et-Loire, G 10 (avec 56 prêtres ordonnés entre septembre et décembre 1467), et G 11 (417 prêtres dans l'année 1521-1522). 
toire des sociétés des villes et des villages des campagnes dans une région donnée. Là où elles existent, les collégiales sont des cellules dynamiques de la vie religieuse et sociale, et par leur intégration aux activités du marché, elles ont une fonction économique de premier plan. Au nombre des questions qui mériteraient d'être fouillées plus avant, il conviendrait ainsi d'inscrire l'étude du rôle des chapitres dans la reconstruction rurale à la fin du Moyen Âge.

\title{
Pièce justificative \\ Fondation du chapitre de la Grésille (27 octobre 1455)
}

\author{
A. Original perdu \\ B. Copie XVII ${ }^{\mathrm{e}}$ siècle, papier : Arch. dép. Maine-et-Loire, G 1321 \\ C. Copie, XVII siècle, papier : Arch. dép. Maine-et-Loire, H 2794, f ${ }^{\circ}$ 104-110 \\ D. Copie, XVII ${ }^{\mathrm{e}}$ siècle, papier : Arch. dép. Maine-et-Loire, E 4084 \\ E. Copie, fin XVII ${ }^{\mathrm{e}}$ siècle, papier : Arch. dép. Maine-et-Loire, 35 G 4
}

$\left(f^{\circ}\right.$ 1) Sachent tous presents et à venir qu'en nostre court à Angers, en droit par devant nous personnellement constituée et establie noble et puissante dame Anne de la Grezille, dame dudit lieu de la Grezille ${ }^{100}$, d'Ardane ${ }^{101}$, de Concourson ${ }^{102}$ et de la Varraine ${ }^{103}$, suffizamment authorisée de par le roy nostre souverain seigneur pour l'ocupation pour cause de malladie de noble et puissant messire Anthoine Turpin, chevalier, seigneur de Crissé ${ }^{104}$, son mary et espoux, sy comme elle dit soumettant soy ses hoirs avecq tous et chascuns ses biens meubles et immeubles presents et advenir, au pouvoir, destroit et juridiction de nostre ditte cour, quand à cest effet confesse de son bon gré sans aulcun pourforcement et de propos deliberé, tant pour accomplir la vollonté et ordonnance de noble et puissant seigneur feu Geoffroy de la Grezille son pere, en son vivant seigneur desdits lieux de la Grezille, de Concourson et de la Varraine, lequel comme elle disoit avait engaigé à sondict espoux et elle de faire et accomplir les choses dont sera cy apprès parlé, et dont ils s'estoient chargés et l'avoient promis faire, que pour accomplir leurs dires et promesses qu'ils avoient faictes audit feu Geoffroy de la Grezille, à la descharge de leurs conscience, aussi pour l'ocguementation du service divin et pour le salut et remede des ames dudict deffunct de la Grezille, de leurs aultres predecesseurs et amis trespassés, d'eux et de leurs successeurs, qu'elle a voulu et ordonné et par $\left(\mathrm{f}^{\circ} 1 \mathrm{v}\right)$ ces presentes veule et ordonne licence, et en cas qu'il plaira à reverand pere en Dieu l'evesque d'Angers, ordinaire en cette partie, un college estre fondé et lequel elle fonde et dès à present la licence dessusdite auduct lieu de la Grézille, près le chastel, au dioceze d'Angers, en la chapelle qui est de present, de cinq chapelains prebstres et de deux clers choreaux, bacheliers si experz et idoiennes qu'il puisse ayder à faire et continuer le service divin dudict college comme deux chapelains, excepté de

100. La Grésille, commune de Ambillou-Château, Maine-et-Loire, canton de Gennes. 101. Ardennes, faubourg de Montreuil-Bellay, Maine-et-Loire, chef-lieu de canton.

102. Concourson-sur-Layon, Maine-et-Loire, canton de Doué-la-Fontaine.

103. La Varenne, commune de Charcé-Saint-Ellier, Maine-et-Loire, canton de Thouarcé.

104. Crissay-sur-Manse, Indre-et-Loire, canton de l'Isle-Bouchard. 
celebrer messe en l'honneur de Dieu et de la benoiste Vierge Marie et de toute la cour celestiel.

Et qu'en l'eglize dudict college, au grand et principal autel, soit l'image de la Vierge Marie comme principalle patronne de laditte esglize collegiale. Lesquels cinq chapelains et deux choreaux seront tenus dire, faire et celebrer par chascun jour, à jamais et perpetuellement, le divin service qui s'ensuict, selon l'usage et l'observance de l'Eglise d'Angers; c'est à scavoir matines à nottes, la messe de Nostre Dame à l'issue des matines, prime, tierce, sexte et nonnes, la grande messe de cœur, vespres et complie, le tout à hault voix et à nottes, et toutes les sollennités et ceremonies de festes de l'an autant qu'ils le pourront faire; et oultre diront à nottes les heures de Nostre Dame, tout ainsy qu'il est accoutumé de faire es esglizes collegialles d'Angers.

Et pour ce que le curé de l'eglize paroissialle d'Ambillou, en laquelle paroisse le chastel de la Grezille et laditte chapelle sont sittués, et les successeurs curés de laditte cure par avant ce faict estoient tenus dire et celebrer par eux ou par leurs chapelains chascun jour de l'an perpetuellement en laditte chapelle de la Grezille plusieurs services divins, c'est à scavoir par chascun jour de l'an messe basse et à certaines festes messes à nottes, vespres et matines, lesquelles services divins ont esté ( $\left.f^{\circ} 2\right)$ fondés et ordonnés par les seigneurs pour le temps du lieu de la Grezille, lesquels y ont transportés, laissés et ordonnés plusieurs de leurs biens et mesmement dix septiers de froment, six septiers de seigle, et deux pippes de vin de rentes à payer icelluy blé et vin par chascun an audit curé par ledit seigneur ou dame de la Grezille; laditte dame a voullu et veult que ledit curé soit l'un desdits cinq chapelains, et que luy et ses successeurs curés de laditte cure soient deschargés de tout le service qu'ils debvoient et avoient accoustumés de faire en laditte chapelle, par ainsy que le curé de laditte paroisse perpetuellement servira et celebrera par luy ou aultre chapelain son comis le service divin en laditte esglize collegiale en son rang et en la sepmaine tout ainsy que sera chascun desdits aultres chapelains, et au moien que lesdittes deux pippes de vin, dix septiers de froment et six septiers de seigle de rente que ledict curé avoit chascun an par la main du seigneur ou dame de la Grezille par avant cette fondation seront convertis et cette fondation et seront distribués par egalle portion entre lesdits curé et quatre chapelains dessusdiz. Et touttes les oblations qui seront faites en laditte eglize collegiale seront convertis au profict de la fabricque dudict college, excepté les oblations du jour de Noël qui chascun an appartiendront et demeureront audit curé et à ses successeurs. Et à cette presente fondation a esté present soy et consenty messire Estienne Laittault, prebtre à présent curé de laditte paroisse d'Ambillou et pour soy departir et percevoir à son singullier proffict et qu'il delaisse lesdittes oblations à laditte fabricque et soy consentir à cette presente fondation; ledict curé ny ses successeurs ne seront tenus doresnavant d'une lampe que laditte dame disoit qu'il estoit tenu de fournir en laditte chapelle, et ne pouront laditte dame, ses hoirs et ayant causes, demander $\left(\mathrm{f}^{\circ} 2 \mathrm{v}\right)$ audit curé ny à ses successeurs aulcune choses pour raison de ladite lampe, ny d'une dixme qu'elle dit qui fu donnée aux predecesseurs dudit curé pour le service qu'il sauroit faire en laditte chapelle, lequel service il sera tenu faire et continuer par luy ou par aultre ainsy qu'il vouloit jusque à ce que ledit service collegial soit encommencé à faire comme dit est. Et s'il advenoit que par aulcun cas cette presente fondation ne sortit son effet, ledict curé d'Ambillou seroit tenu celebrer par luy ou par aultre le service qu'il estoit tenu faire en laditte chapelle avant cette presente fondation et ordonnance, et aussy il auroit et percevroit lesdits seize septiers de blé et deux pippes de vin ainsy qu'il faisoit auparavant cette presente fondation. 
Et pour faire et celebrer ledit service collegial et pour la substantation desdits quatre chapelains, curé et choreaux, laditte dame a transporté, ceddé, laissé, ordonné, deputté, et par ces presente donne, transporte, cedde, laisse, ordonne et deputte toutes et chascune les choses qui s'ensuivent. C'est à scavoir que la dixme des blés de Doué ${ }^{105}$ appartenant à laditte dame de la Grezille au fief de Doué tenue d'elle sous l'homaige de Concourson appartenante à laditte dame, vallant chascuns ans six vingt septiers de blé à la mesure de Doué, qui peult valloir communs ans cent livres de rente.

Item, la dixme des bleds d'Islay ${ }^{106}$, en la paroisse d'Ambillou, size au fief de la Grezille, appartenant à laditte dame, montant à quarente septiers de froment par chascun an, mesure de Brochesac ${ }^{107}$, vallant chascuns ans quarente livres.

Item, une aultre dixme de blé appartenant à laditte dame, size en laditte paroisse au bourg Davau, audit lieu d'Ambillou au fief de la Grezille, vallant chascuns ans soixante sols de rente.

Item, la dixme des bleds de Touarcé ${ }^{108}$ sise au fief de Vezins ${ }^{109}$, tenue d'illeq à foy et homaige, vallant chascuns ans soixante septiers de blé, mesure de la Grezille, [ $f^{\circ} 3$ ] et ce compris une petite dixme qui est à Sourdigné ${ }^{110}$ et la Moriellerie vallant chascuns ans trante cinq livres.

Item, la dixmes de vin de Touarcé appartenant à laditte dame, size au fief de Vezins et tenue d'illec sous le seul et mesme homaige avecq la dixme des blés dessus dite, qui vault chascuns ans douze ou treze pippes de vin, sur laquelle dixme est deue à Saint-Maurice ${ }^{111}$ d'Angers par chascun an la somme de cent sols tournois, vallant laditte dixme chascuns ans vingt cinq livres tournois laditte somme de cent sols payée.

Item, la dixme de vin appartenant à laditte dame en la paroisse d'Ambillou, au fief de la Grezille, vault chascuns ans deux pippes de vin valant six livres de rente, lesquelles choses sont de l'heritage de laditte dame sy comme elle dit.

Item, sept quartiers de vignes appelées les Vignes Rouges que laditte dame dit avoir acquise de Geoffroy Boishubert, sittuée en la paroisse de Concourson, joignant d'un costé la vigne de Jean Berthelot paroissien de Doué, d'autre aux prés de l'houstel de Concourson, abouttant d'un bout aux prés du curé de Doué, et d'aultre les vignes de Hamon du Portau, vallant dix livres de rente.

Item, dix livres de rente que feu dame Jeanne de Brezé, dame de la Grezille, ordonna pour une chapelainie à la charge de deux messes estre celebrées en laditte esglize de la Grezille.

Item, aultre dix livres de rente que feu dame Jeanne Oudarde, dame de la Grezille, mere de laditte dame, ordonna à la semblable charge de deux messes estre celebrées en laditte chapelle de la Grezille, lesquelles rentes de vingt livres ordonnées pour fonder lesdittes deux chapelainies. Laditte dame sera tenue payer par [ $\left.\mathrm{f}^{\circ} 3 \mathrm{v}\right]$ jamais jusque à ce qu'elle aist baillé assiette de debvoir ausdits chapelains.

105. Doué-la-Fontaine, Maine-et-Loire, chef-lieu cant.

106. Islay, commune d'Ambillou, ancien fief appartenant à la seigneurie de Maurepart en Brigné (PoRT, Célestin, Dictionnaire historique, géographique et biographique de Maineet-Loire, $2^{\mathrm{e}}$ éd., t. 2, Angers, 1965, p. 296-297)

107. Brissac, Maine-et-Loire, canton de Thouarcé.

108. Thouarcé, Maine-et-Loire, chef-lieu de canton.

109. Vezins, Maine-et-Loire, canton de Cholet est.

110. Sourdigné, commune Valanjou, Maine-et-Loire, canton de Thouarcé.

111. La cathédrale d'Angers. 
Item, la terre de Magerve vallant quarante livres de rente ou environ, laquelle fu naguere ordonnée par ledict feu Geoffroy de la Grezille pour la fondation d'une chapelainie à la charge de deux messes estre deservie en laditte chapelle de la Grezille, laquelle desert à present messire Jean Bigot, lequel sera un desdits chapelains ou chanoines sy comme dit laditte dame.

Touttes lesquelles choses peuvent valloir la somme de treze vingts dix neuf livres de rente par chascun an, en oultre lesdits seize septiers de blé et deux pippes de vin de rente que ledict curé a rapporté à cette fondation, que dit est lesquelles rentes de seize septiers de blé et deux pippes de vin laditte dame, ses hoirs et ayant causes payront chascun an auxdits chapelains, qui pouroient valloir chascuns ans vingt livres de rente. Et pour ce toutte laditte fondation monteroit chascun an tout la somme de trois cent livres de rente, de laquelle somme chascun desdits curé, chapelains ou chanoines pouront avoir quarente livres de rente par chascun an, et chascun des choreaux quinze livres de rente qui semble estre suffizante dotation.

Item et d'icelle somme de trois cent livres a ordonné laditte dame dix livres par chascun an, tant pour fournir deux lampes; l'une ardera jour et nuit davant le grand autel, et l'aultre durant que l'on dira le divin service, qu'aussy pour garnir de luminaire de cire convenable par chascun an à laditte esglize collegiale. Item, pour celluy qui sera segrettain de laditte esglize collegiale, comme cy après sera dit, dix livres de rente, lesquelles mises se montent à deux cent cinquante livres, ainsy resteroit cinquante livres de laditte somme de trois cent livres pour fournir et supler aux [ $\left.\mathrm{f}^{\circ} 4\right]$ necessitées qui pourroient survenir audit college.

Item, laditte dame a promis et promet par ces presente faire croistre laditte chapelle, et y faire faire le cœur à dire le divin service bien et honorablement, et faire achever les maisons pour habitter lesdicts chapelains ou chanoines, lesquelles sont grandement encommencées; lesquelles elle a donné et donne auxdicts chapelains et leurs successeurs avecq les jardins desdittes maisons, et aussy a promis et promet garnir de livres et ornemens et aultres choses à ce convenable.

Item, et affin que ledict service soit par ordre et convenablement fait par chascun desdits chapelains ou curé ou comis dudit curé pour luy en son rend et en son tour, sera semeinier et commensera ledit service, dira ou fera dire la messe de jour avec les vespres et autres heures, et les autres luy aideront; et quy ny sera present ne prendera rien à la distribution de l'heure où il defaudera, et les deffautz seront au proffict de la fabrice de laditte esglize collegiale, laquelle distribution poura valloir deux sols chascun pour chascun desdits chapelains; et les autres qui ne seront pas semeinier et seront tenus celebrer laditte messe Nostre Dame chascun en son rang, lesquelles chapelains et choreaux seront tenus faire personnelle et continuelle rezidence sur le lieu dudit college, sur peine d'estre privé de leurs fruits et distributions. C'est à scavoir ledit curé par luy ou autre chapelain suffizant tel qu'il luy plaira, et les aultres quatre chapelains en leurs personnes, et sy aulcun d'eux estoit absent pour un mois sans licence des autres, l'on pouroit procedder contre luy à la privation de son benefice, et ne pouront donner licence aulcuns d'eux par quoy le service divin cesse. Et affin que service soit ordonné à cause desdits trois chapelains dont sy dessus est fait mention soit dit et celebré, c'est à scavoir pour chacune desdittes chapelainies une messe basse par chascune sepmaine, laditte dame a ordonné que chascun desdits trois chapellains qui ne seront pour lors semeiniers $\left[\mathrm{f}^{\circ} \mathrm{kv}\right.$ ] ny chargés de dire messe de Nostre Dame, dire deux desdittes basse messe chascun d'eux en son rend. Et seront lesdits quatre chapelains ou chanoines et le comis dudit curé prebtres, aultrement ils ne seront point institués.

Item, et pour clorre et ouvrir laditte esglize collegiale, pour garder les calices, livres, ornements et autres choses necessaires à tout ce que dit est, et pour sonner les cloches aux heures, laditte dame a ordonné que l'un d'iceux chapelains, 
lequel ils eliront entre eux, soit segrettain et exerce l'office de segretain qui sera office perpetuel; et pour ce faire, il aura laditte somme de dix livres dont cy dessus est faict mention, et oultre la recompense comme chascun desdits chapelains. Et sy ne peuvent s'accorder en laditte eslection, ledit reverand pere en Dieu y pourvoira un mois passé apprès la vacation.

Item, que lesdicts chapelains ou chanoines et choreaux seront tenus celebrer quatre anniversaires solennelles pour chascun an de trois mois en trois mois pour l'ame desdits fondateurs dudict college et parants et amis trespassés. Et pour les dimanches, procession et à la fin d'icelle, le respont avecq le verset et oraison des deffuncts pour l'ames desdicts fondateurs, leurs parants et amis trespassés selon l'observance de l'Esglize d'Angers.

Et a promis et promet laditte dame par ces presentes faire amortir et indemniser à ses prospres despens touttes les choses dessusdittes par elle ordonnées et transportées en nostre presente fondation et ordonnance. Et en cas que lesdittes choses ne vauderont laditte somme de trois cent livres de rentes, laditte dame a promis les parfaire et bailler ce qui deffaulderoit en bonne et suffizante assiette, et payer par les mains ce qui deffauderoit jusque à ce qu'elle aist faict assiette, et le tout admortir et indamner comme dessus est dit.

Et a voullu et ordonné, veult et ordonne par ces presantes laditte dame que la presentation desdits chapelains et chanoines, excepté la chapelainie et prebende dudit curé qui est annexée [ $\mathrm{f}^{\circ} 5$ ] à laditte cure, soit et appartienne à elle comme dame de la Grezille et apprès son deced à son herittier et seigneur dudit lieu de la Grezille, et la collation et institution d'iceux chapelains à reverand pere en Dieu l'evesque d'Angers, moyennant laditte presentation et institution desdits choreaux bacheliers à elle et apprès son deced à son heritier seigneur dudit lieu de la Grezille, avec le consentement desdits chapelains. Et supplie icelle audit reverand pere en Dieu l'evesque d'Angers et en son absence à honnorables hommes ses vicaires que leurs plaisent ratiffier et approuver ceste presente ordonnance et fondation et tout ce que dit est, et sur ce indeposer son decret, et qu'il luy plaise es lieu de procuration qu'il pouroit prendre et avoir chascun an sur ledit college soy contenter d'avoir chascun an pour lui et ses successeurs soixante sols tournois de pension au jour de saint Lucas ${ }^{112}$, payables par lesdits chapelains sur le revenu dudit college. Et a ordonné et ordonne laditte dame que ledict reverand pere en Dieu et ses successeurs, et pour et en recompensation des relations de remission de ses droits qu'elle supplie estre faicts touchants ledit college, et aussy que ledict reverand pere en Dieu est descendu et extrait de ceux de Beauvau ${ }^{113}$, prochaint parant et lignager desdicts de la Grezille, soient sensés et reputtés principaux fondeurs et bienfaicteurs dudict college après laditte dame, et singullierement participant des bienfaicz et prieres d'icelluy.

Lesquelles choses ainsy transportées, ceddées et delaissées comme dit est, laditte a promis et promet faire valloir, garantir et deslivrer et deffendre vers tous et contre tous de tous quelconques [ $\mathrm{f}^{\circ} 5 \mathrm{v}$ ] empeschement, et à tout ce que dessus est dit tenu et devisé, tenir, faire, promettre et accomplir, laditte dame a obligé et oblige par ces presants elle, ses hoirs et ayant causes, ses biens et choses meubles et immeubles presentes et advenir quels qu'ils soient, et a renoncé et renonce par devant nous quand pour cest effet à touttes et chascunes les choses que contre la teneur, forme et substance de ces presants pouroient estre dittes, pro-

112. Le 18 octobre, date - avec la Pentecôte - de l'un des deux synodes annuels dans le diocèse d'Angers.

113. Jean de Beauvau, évêque d'Angers (1447-1467) puis administrateur du diocèse entre 1476 et 1479 . 
posées, objectées et alleguées en aulcusne maniere et à tout ce faire et garder, tenir et entretenir et accomplir est tenue laditte dame par la foy, serment de son corps sur ce donné en nostre mein et à sa requeste jugée et condennée par le jugement et condennation de nostre cour. Et pareillement ledict Laittault de son consentement en a esté jugé et quand à ce s'est soumis à laditte juridiction, ce faict donné en double.

Faict audit lieu de la Grezille, es presence dudict reverand pere en Dieu, et honnorable homme et sage messire Jean Haberge conseiller du roy en la cour de Parlement, Guillaume de Saint-Just chantre et chanoine de l'Esglize d'Angers, Robert Assé provost d'Anjou en l'esglize de Saint-Martin de Tours, messire Jean Bellanger docteur es droict civil, maistre Jean Rocher archeprestre de Saumur, messire Jean Lhuillier docteur en theologie, et ledict Laittault curé d'Ambillou à ce presant et consentant, et plusieurs aultres à ce presants et appelés.

Le vingt septiesme jour d'octobre, l'an mil quatre cent cinquante cinq. Signé $\left(f^{\circ} 6\right)$ en la grosse de ces presants, J. Mireleau et Perigault, et scellée en double queue de cire verte. 


\section{RESUME}

Cet article s'applique à démontrer les traits fondamentaux de l'histoire des églises collégiales du diocèse d'Angers au Moyen Âge, depuis leur fondation jusqu'à la veille de la Réforme. Plusieurs problèmes sont étudiés successivement. D'abord, les circonstances locales des fondations aux $\mathrm{XI}^{\mathrm{e}}$-XII ${ }^{\mathrm{e}}$ siècles, et à la fin du Moyen Âge. Ensuite, l'organisation interne des chapitres et la question du recrutement des chanoines, avec une attention particulière pour le niveau social et culturel du recrutement, l'origine géographique ou le respect de l'obligation de résidence. Pour finir, l'étude envisage les différentes fonctions des églises de chanoines dans la société de la fin du Moyen Âge, dans le domaine religieux comme dans l'histoire de la société ou de l'économie.

\section{ABSTRACT}

This study seeks to demonstrate the fundamental traits of the history of collegial churches in the diocese of Angers in the Middle Ages, since their fundation to the eve of Reformation. Different problems are studied. The local circumstances of the fundations in the XIth and XII th centuries and in the later Middle Ages. Then, the internal organisation of the chapters, with a particular attention for recruitment problems such as social and cultural level, geographical origin as well as their respect for the rule of residence. The last chapter of this study reveals the different functions of chapters of canons in society of the later Middle Ages, in religious area such as social or economic history. 
